\title{
Dioxygen Activation Kinetics over Distinct Cu Site Types in Cu-CHA Zeolites
}

\author{
Daniel T. Bregante, ${ }^{1, \pi}$ Laura N. Wilcox, ${ }^{2, \pi}$ Changming Liu, ${ }^{3}$ Christopher Paolucci, ${ }^{3}$ Rajamani \\ Gounder,2 David W. Flaherty ${ }^{1, *}$ \\ ${ }^{1}$ Department of Chemical and Biomolecular Engineering, University of Illinois at Urbana-Champaign, Urbana, IL \\ 61801
}

${ }^{2}$ Charles D. Davidson School of Chemical Engineering, Purdue University, West Lafayette, IN 47907

${ }^{3}$ Department of Chemical Engineering, University of Virginia, Charlottesville, VA 22904

TD.T.B. and L.N.W. contributed equally to this work

KEYWORDS: Cu-SSZ-13, partial methane oxidation, Raman spectroscopy, spectrokinetics, in situ spectroscopy

\begin{abstract}
Cu}$-exchanged zeolites activate dioxygen to form active sites for partial methane oxidation (PM0), nitrogen oxide decomposition, and carbon monoxide oxidation. Apparent rates of $\mathrm{O}_{2}$ activation depend both on the intrinsic kinetics of distinct $\mathrm{Cu}$ site types and the distributions of such sites within a given zeolite, which depend on the density and arrangement of the framework $\mathrm{Al}$ atoms. Here, we use hydrothermal synthesis methods to control the arrangement of framework $\mathrm{Al}$ sites in chabazite (CHA) zeolites and, in turn, the distinct $\mathrm{Cu}$ site types formed. Time-resolved in situ resonance Raman spectroscopy reveals the kinetics of $\mathrm{O}_{2}$ adsorption and activation within these well-defined $\mathrm{Cu}-\mathrm{CHA}$ materials and the concomitant structural evolution of copper-oxygen $\left(\mathrm{Cu}_{x} \mathrm{O}_{y}\right)$ complexes, which are interpreted alongside $\mathrm{Cu}(\mathrm{I})$ oxidation kinetics extracted from in situ X-ray absorption spectroscopy (XAS). Raman spectra of several plausible $\mathrm{Cu}_{\mathrm{x}} \mathrm{O}_{\mathrm{y}}$ species simulated using density functional theory suggest that experimental spectra $\left(\lambda_{\mathrm{ex}}=532 \mathrm{~nm}\right)$ capture the formation of mono( $\mu$-oxo)dicopper species (ZCuOCuZ). Transient experiments show that the timescales required to form $\mathrm{Cu}_{\mathrm{x}} \mathrm{O}_{\mathrm{y}}$ structures that no longer change in Raman spectra correspond to the durations of oxidative treatments that maximize $\mathrm{CH}_{3} \mathrm{OH}$ yields in stoichiometric PMO cycles (approximately $2 \mathrm{~h}$ ). Yet, these periods extend well beyond the timescales for the complete conversion of the initial $\mathrm{Cu}(\mathrm{I})$ intermediates to their $\mathrm{Cu}(\mathrm{II})$ states $\left(<0.3 \mathrm{~h}\right.$, reflected in XANES spectra), which demonstrates that $\mathrm{Cu}_{\mathrm{x}} \mathrm{O}_{\mathrm{y}}$ complexes continue to evolve structurally following rapid oxidation. The dependence of $\mathrm{ZCuOCuZ}$ formation rates on $\mathrm{O}_{2}$ pressure, $\mathrm{H}_{2} \mathrm{O}$ pressure, and temperature are consistent with a mechanism in which $\mathrm{ZCuOH}$ reduce to form $\mathrm{ZCu}^{+}$sites that bind molecular oxygen and form $\mathrm{ZCu}-\mathrm{O}_{2}$ intermediates. Subsequent reaction with proximate $\mathrm{ZCu}^{+}$form bridging peroxo dicopper complexes that cleave $\mathrm{O}-\mathrm{O}$ bonds to form $\mathrm{ZCuOCuZ}$ in steps facilitated by water. These data and interpretations provide evidence for the chemical processes that link rapid and kinetically irrelevant Cu oxidation steps (frequently probed by XAS and UV-Vis spectroscopy) to the relatively slow genesis of reactive $\mathrm{Cu}$ complexes that form $\mathrm{CH}_{3} \mathrm{OH}$ during PMO. In doing so, we reveal previously unrecognized complexities in the processes by which $\mathrm{Cu}$ ions in zeolites activate $\mathrm{O}_{2}$ to form active $\mathrm{Cu}_{\mathrm{x}} \mathrm{O}_{\mathrm{y}}$ complexes, which underscore the insight afforded by judicious combinations of experimental and theoretical techniques.
\end{abstract}

\subsection{INTRODUCTION}

Copper ions exchanged onto Al-substituted zeolites facilitate various oxidation reactions and redox cycles, including NO decomposition, ${ }^{1-2} \mathrm{CO}$ oxidation, ${ }^{3-4} \mathrm{NO}_{x}(x=1,2)$ selective catalytic reduction using $\mathrm{NH}_{3},^{5-9}$ and the partial oxidation of $\mathrm{CH}_{4}$ to form $\mathrm{CH}_{3} \mathrm{OH}$ in stoichiometric ${ }^{10-17}$ and catalytic ${ }^{18-19}$ cycles. In the context of partial methane oxidation (PMO), $\mathrm{Cu}(\mathrm{II})$ ions reduce to their $\mathrm{Cu}(\mathrm{I})$ states at high temperatures (e.g., $723 \mathrm{~K}$ in He, ${ }^{14,17,20-21} 523 \mathrm{~K}$ in $5 \% \mathrm{CO}^{20,22}$ ) prior to exposure to extended $\mathrm{O}_{2}$ activation treatments (e.g., $723 \mathrm{~K}$, > $2 \mathrm{~h}$ ) that form active multinuclear $\mathrm{Cu}(\mathrm{II})$ species $\left(\mathrm{Cu}_{\mathrm{x}} \mathrm{O}_{\mathrm{y}}\right)^{1{ }^{14}}$, ${ }^{21}$ At lower temperatures, these $\mathrm{Cu}_{x} \mathrm{O}_{\mathrm{y}}$ intermediates react readily with $\mathrm{CH}_{4}$ to form surface methoxy-derived species (e.g., complete consumption within $0.5 \mathrm{~h}$ at $473 \mathrm{~K}$ ), which desorb as $\mathrm{CH}_{3} \mathrm{OH}$ upon contact with $\mathrm{H}_{2} \mathrm{O}$ in vapor or liquid phases. The dependence of methanol yields (per $\mathrm{Cu}$ ) on reaction conditions (e.g., reactant pressure, temperature, time) has been well studied;11, 14, 17, 23-24 however, comparatively few investigations describe the series of steps responsible for the activation of $\mathrm{O}_{2}$ molecules or the kinetics and formation of active $\mathrm{Cu}_{\mathrm{x}} \mathrm{O}_{\mathrm{y}}$ complexes. ${ }^{11,22,24}$

Nearly two decades of research have sought to identify the $\mathrm{Cu}_{\mathrm{x}} \mathrm{O}_{\mathrm{y}}$ species that form upon $\mathrm{O}_{2}$ activation treatments of $\mathrm{Cu}$-exchanged zeolites and produced numerous proposals (e.g., bis( $\mu$-oxo)dicopper, ${ }^{1,} 10$ mono( $\mu$-oxo)dicopper, ${ }^{11}, 13,16,22-24 \mu-\left(\eta^{2}: \eta^{2}\right)$ peroxo dicopper, ${ }^{25}$ trans- $\eta-1,2-$ peroxo dicopper, ${ }^{13}, 22$ bis( $\mu$-hydroxyl)dicopper ${ }^{26}, \operatorname{mono}(\mu$ oxo)tricopper 27-29). Initial reports from Groothaert et al. combined in situ extended X-ray absorption fine structure (EXAFS), UV-Vis-near-IR, and electron paramagnetic 
resonance (EPR) spectroscopies with comparisons to dicopper metalloenzymes to assign a $22,700 \mathrm{~cm}^{-1} \mathrm{UV}-\mathrm{Vis}$ absorbance feature observed on $\mathrm{O}_{2}$-activated $\mathrm{Cu}$-ZSM-5 to a bis( $\mu$-oxo)dicopper species. ${ }^{1,10}$ Solomon and coworkers utilized resonance Raman spectroscopy and DFT from which they concluded a bent mono-( $\mu$-oxo)dicopper forms upon $\mathrm{O}_{2}$ activation over $\mathrm{Cu}-\mathrm{ZSM}-5^{11,23}$ and Cu-MOR. ${ }^{24}$ Recently, van Bokhoven and coworkers examined the formation of PMO active sites in MOR and MAZ zeolites and proposed that proximal $[\mathrm{CuOH}]^{+}$species form bridged $\mathrm{Cu}$-oxo type species using X-ray powder diffraction, DFT, and XAS .26, 3031 Additionally, Pappas et al. studied $\mathrm{Cu}-\mathrm{MOR}^{13}$ and $\mathrm{Cu}-$ $\mathrm{CHA}^{14}$ zeolites with varying $\mathrm{Cu}$ and $\mathrm{Al}$ content and found that $\mathrm{O}_{2}$ activation requires two $\mathrm{Cu}$ centers (i.e., to form mono( $\mu$-oxo $)$ dicopper or trans- $\eta-1,2$-peroxo dicopper) by using in situ X-ray absorption (XAS) and resonance Raman spectroscopies. Lobo and coworkers studied the small-pore zeolite $\mathrm{Cu}$-CHA using Raman spectroscopy to identify vibrational features for trans- $\mu-1,2-$-peroxo dicopper and mono( $\mu$-oxo)dicopper, identifying the vibrational features of the latter using ${ }^{18} 0$-atoms and DFT calculations. ${ }^{22}$ In this study, mono-( $\mu$-oxo)dicopper was determined to be the most stable $\mathrm{Cu}_{\mathrm{x}} \mathrm{O}_{\mathrm{y}}$ site formed as Raman spectra of the $\mathrm{O}_{2}$-activated sample remained unchanged after four days in $\mathrm{O}_{2}$ at ambient temperature. In contrast, Lercher and coworkers implicated mono( $\mu$-oxo)tricopper intermediates in both $\mathrm{Cu}$-ZSM$5^{28}$ and $\mathrm{Cu}-\mathrm{MOR}^{27,29}$ based on $\mathrm{Cu}$-normalized stoichiometric $\mathrm{CH}_{3} \mathrm{OH}$ yields $\mathrm{CO}_{2}$ activation: pure $\mathrm{O}_{2}, 723 \mathrm{~K}, 1 \mathrm{~h}$; $\mathrm{CH}_{4}$ introduction: $91.2 \mathrm{kPa} \mathrm{CH}_{4}$ balance $\mathrm{He}, 473 \mathrm{~K}, 4 \mathrm{~h}$; $\mathrm{CH}_{3} \mathrm{OH}$ extraction: equimolar $\mathrm{H}_{2} \mathrm{O}$ and $\mathrm{He}, 408 \mathrm{~K}, 0.5 \mathrm{~h}$ ) that correlated linearly with one-third of the total $\mathrm{Cu}$ content, consistent with structures identified within in situ EXAFS spectra during $\mathrm{O}_{2}$ activation. Taken together, this series of contributions presents compelling evidence for multiple and seemingly contradictory conclusions regarding the identity of $\mathrm{Cu}_{\mathrm{x}} \mathrm{O}_{\mathrm{y}}$ species formed upon $\mathrm{O}_{2}$ activation over $\mathrm{Cu}$-zeolites, which remains an important area for continued investigation.

The ability of $\mathrm{Cu}$ species to bind $\mathrm{O}_{2}$, cleave the $0-0$ bond, and form distinct $\mathrm{Cu}_{\mathrm{x}} \mathrm{O}_{\mathrm{y}}$ structures depends strongly upon the spatial and crystallographic distribution of the $\mathrm{Al}$ atoms within the zeolite and the fraction of this distribution associated with $\mathrm{Cu}$ ions. ${ }^{20}$ The $\mathrm{Al}$ distribution in a given zeolite depends on its bulk $\mathrm{Si} / \mathrm{Al}$ ratio and framework topology, and the conditions used for its synthesis, which can collectively lead to significant $\mathrm{Cu}$ site heterogeneity among experimental studies. Divalent copper complexes are particularly sensitive to non-uniformities in the arrangement of $\mathrm{AlO}_{4}$ sites, because they either require charge compensation from two $\mathrm{AlO}_{4}^{-}$centers or coordination to anionic ligands if only one $\mathrm{AlO}_{4}^{-}$center is present. As stated by Borfecchia et al., the differences between the many proposals for active $\mathrm{Cu}_{\mathrm{x}} \mathrm{O}_{\mathrm{y}}$ sites for stoichiometric PMO cycles likely reflect complexities both among the zeolite topologies studied (e.g., ZSM-5, MOR, CHA) and among the varied reaction protocols used (e.g. $\mathrm{O}_{2}$ activation conditions, $\mathrm{CH}_{4}$ reaction conditions). ${ }^{32}$

The high symmetry chabazite (CHA) framework provides a model material to study the nature of $\mathrm{O}_{2}$ activation, because CHA contains a single crystallographically unique tetrahedral site. Moreover, CHA zeolites can be synthesized intentionally with precise control over the relative proximity of framework Al atoms. ${ }^{33-34}$ For example, Dusselier and coworkers used this capability to demonstrate on Fe-CHA zeolites that paired $\mathrm{Al}$ atoms in the 6-membered ring (MR) (i.e., in second- or third-nearest neighbor configurations) stabilize the PMO active site ( $\alpha$-Fe) and correlate to $\mathrm{CH}_{3} \mathrm{OH}$ yields (per Fe) from PMO cycles. ${ }^{34}$ Well-defined Cu-CHA materials with controlled speciation of $\mathrm{Cu}$ ions can be synthesized wherein 6-MR paired $\mathrm{Al}$ sites (2 Al per 6-MR) exchange $\mathrm{Cu}^{2+}$ ions $\left(\mathrm{Z}_{2} \mathrm{Cu}\right),{ }^{7}$ while 6 -MR isolated framework $\mathrm{Al}$ atoms (1 Al per 6-MR) nominally exchange [CuOH$]^{+}$species $(\mathrm{ZCuOH})$. Upon $\mathrm{O}_{2}$ activation of $\mathrm{Cu}-\mathrm{CHA}$, a fraction of $\mathrm{ZCuOH}$ species form binuclear $\mathrm{O}_{2}$-bridged structures observed within in situ UV-Vis spectra, while $\mathrm{Z}_{2} \mathrm{Cu}$ sites do not. ${ }^{20}$ These findings agree with reports $\mathrm{Z}_{2} \mathrm{Cu}$ sites do not participate in PMO. 14-15, 17 The elementary steps by which $\mathrm{O}_{2}$ activates over $\mathrm{ZCuOH}$ sites to form PMO-active species, ${ }^{35-36}$ however, remain elusive.

Here, we use time-resolved in situ resonance Raman spectroscopy to measure the spectrokinetics of $\mathrm{O}_{2}$ activation over well-defined $\mathrm{Cu}$-CHA materials that contain predominantly $\mathrm{Cu}$ either at 6-MR isolated or paired $\mathrm{Al}$ sites, or mixtures thereof. In situ Raman spectroscopy demonstrates that mono( $\mu$-oxo)dicopper complexes form over extended periods $(2-6 \mathrm{~h})$ similar to those needed to maximize $\mathrm{CH}_{3} \mathrm{OH}$ yields, which suggests the $\mathrm{Cu}_{\mathrm{x}} \mathrm{O}_{\mathrm{y}}$ complexes detected by Raman correspond to the $\mathrm{Cu}(\mathrm{II})$ species responsible for PMO. In contrast, in situ XAS measurements indicate that $\mathrm{Cu}(\mathrm{I})$ converts to $\mathrm{Cu}(\mathrm{II})$ intermediates $\left(\mathrm{Cu}-\mathrm{O}_{2}\right.$; e.g., $\mu$ $\left(\eta^{2}: \eta^{2}\right)$ peroxo dicopper) on much shorter timescales $(<0.3$ h), and therefore, the $\mathrm{Cu}(\mathrm{I})$ to $\mathrm{Cu}(\mathrm{II})$ transformation detected by XAS may signify the formation of a precursor to PMO-active sites. The combination of DFT $+U$ computed Raman intensities, steady-state Raman spectra, and ${ }^{18} \mathrm{O}$-labeling suggest $\mathrm{ZCuOH}$ sites activate $\mathrm{O}_{2}$ to form mono( $\mu$-oxo)dicopper species. Rates of formation for the mono( $\mu$-oxo $) \mathrm{di}-$ copper complex are measured as a function of $\mathrm{O}_{2}(5-42 \mathrm{kPa}$ $\mathrm{O}_{2}$ ) and $\mathrm{H}_{2} \mathrm{O}$ pressure $\left(0-1 \mathrm{kPa} \mathrm{H}_{2} \mathrm{O}\right)$ and temperature $(648$ - $773 \mathrm{~K}$ ) to probe the series of chemical transformations that occur during $\mathrm{O}_{2}$ activation. These rates depend on the isotopic substitution of water $\left(k_{H} / k_{D} \geq 2\right)$, which suggests that proton transfer may mediate $0-0$ bond cleavage to form mono( $\mu$-oxo)dicopper species. Collectively, these findings provide evidence for the molecular processes that determine the rates at which PMO-active sites form by interactions with $\mathrm{O}_{2}$ and $\mathrm{H}_{2} \mathrm{O}$ reactants.

\subsection{MATERIALS AND METHODS}

\subsection{Raman Spectroscopy}

Resonance Raman spectra were obtained on a spectrometer (Renishaw, inVia) equipped with a $532 \mathrm{~nm}$ laser. $\mathrm{Cu}-$ CHA samples were first pelletized and sieved to retain $\sim 2$ $\mathrm{mm}$ particles, which were loaded into a temperature-controlled gas-phase reaction cell (Linkam, CCR1000). Cu-CHA samples were first treated to either $723 \mathrm{~K}$ in He (Airgas, Ultra-zero grade; $50 \mathrm{~cm}^{3} \mathrm{~min}^{-1} ; 0.33 \mathrm{~K} \mathrm{~s}^{-1}$ ) and held for $2 \mathrm{~h}$ or to $523 \mathrm{~K}$ in 5\% CO (Airgas, 99.999\%; balance He; $50 \mathrm{~cm}^{3}$ $\mathrm{min}^{-1}$ total flow rate; $0.33 \mathrm{~K} \mathrm{~s}^{-1}$ ) for $1 \mathrm{~h}$. After pretreatments in $\mathrm{CO}$, the sample chamber was purged with $\mathrm{He}\left(50 \mathrm{~cm}^{3} \mathrm{~min}^{-}\right.$ $\left.{ }^{1}\right)$ for $0.5 \mathrm{~h}$ at $523 \mathrm{~K}$. The sample was then heated to a desired temperature in $\mathrm{He}\left(0.33 \mathrm{~K} \mathrm{~s}^{-1}\right)$. Once at the desired $\mathrm{O}_{2}$ - 
activation temperature (648 - $773 \mathrm{~K}$ ), $\mathrm{O}_{2}$ (Airgas, 99.999\%) diluted in He was introduced to the sample to maintain a volumetric flow rate of $50 \mathrm{~cm}^{3} \mathrm{~min}^{-1}$ and $\mathrm{H}_{2} \mathrm{O}(17.8 \mathrm{M} \Omega \cdot \mathrm{cm})$ or $\mathrm{D}_{2} \mathrm{O}$ (Sigma Aldrich, $99.9 \% \mathrm{D}$ atom) was introduced using a syringe pump (KD Scientific, Legato 100) through a liquidinjection port. Simultaneously, spectra $(0.1 \mathrm{~s}, 25$ co-added spectra) were obtained using line-scan mode with a long $50 \mathrm{x}$ objective, such that the power density was approxi-

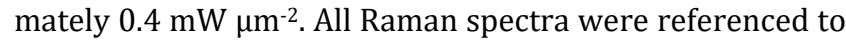
the $520 \mathrm{~cm}^{-1}$ feature of $\mathrm{Si}(111)$. Control experiments which

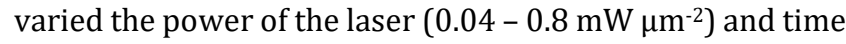
delays between laser exposure indicate that the measured spectra are not affected by localized heating induced from the laser. In our hands, the $\mathrm{CO}$ gas must be purified using a combination of an in-line moisture and $\mathrm{O}_{2}$ trap (Supelco), as well as $\mathrm{Cu}$ turnings (Sigma Aldrich, 99\%) that were heated to $553 \mathrm{~K}$. We observed a discoloration of the Cu-CHA surface, which indicates contamination by metal carbonyls, when these traps were not in place. Other contaminants were removed from the $\mathrm{O}_{2}$ and He streams using inline moisture/hydrocarbon and moisture/hydrocarbon/oxygen combination purifying traps (Supelco), respectively. Consequently, we assume that the partial pressure of $\mathrm{H}_{2} \mathrm{O}$ is $<10^{-4} \mathrm{~Pa}$ (in the absence of intentionally added water vapor), based upon specifications from the gas-trap manufacturers.

The spectral contributions of the independent species formed during $\mathrm{O}_{2}$ activation of $\mathrm{Cu}-\mathrm{CHA}$ were obtained by multivariate curve resolution-alternating least squares (MCR-ALS) performed in the WiRE ${ }^{\mathrm{TM}}$ software package. Iterative fitting procedures, involving up to five components, were used to describe $99.9 \%$ of the data. ${ }^{37}$ In all cases, greater than $90 \%$ of the variance of the measured spectra was described by a single component, while the other extracted spectra primarily represent changes in the baseline during the course of the experiment related to shifts in the sample position or focus over the course of many hours (Section S8).

\subsection{X-Ray Absorption Spectroscopy}

X-ray absorption spectroscopy experiments were performed at the Advanced Photon Source (APS), Argonne National Laboratory in Lemont, Illinois, in sector 10 MR-CAT (Materials Research Collaborative Access Team). The insertion device beamline at sector 10 (10-ID) was used for in situ experiments. A Cu metal foil reference spectrum (edge energy of $8979 \mathrm{eV}$ ) was measured simultaneously with each sample spectrum collected to calibrate the X-ray beam for spectral measurements at the $\mathrm{Cu}$ K-edge. All sample spectra were analyzed in WinXAS and normalized using first and third order polynomials for background subtraction of the pre- and post-edges, respectively. The standards used for linear combination fitting (LCF) of the XANES spectra were $\mathrm{Cu}-\mathrm{CHA}$ dehydrated in $21 \mathrm{kPa} \mathrm{O}_{2}$ (balance $\mathrm{He}$ ) at $723 \mathrm{~K}$ and $\mathrm{Cu}_{2} \mathrm{O}$ (Sigma Aldrich), for $\mathrm{Cu}(\mathrm{II})$ and $\mathrm{Cu}(\mathrm{I})$, respectively, as shown in Figure S9.

Auto-reduction in inert helium (99.999\% UHP), flowed through an oxygen/moisture trap (Matheson, MTRP-0019-
$\mathrm{XX)}$ at a flow rate of $50 \mathrm{~cm}^{3} \mathrm{~min}^{-1}$, was studied at $723 \mathrm{~K}$ (0.167 $\mathrm{K} \mathrm{s}^{-1}$ ) until the XANES spectra stopped changing (sample dependent, up to $2 \mathrm{~h}$ ). For the oxidation treatment, the sample was held in oxygen ( $21 \mathrm{kPa}$ in balance $\mathrm{He}$ ) at a total flow of $50 \mathrm{~cm}^{3} \mathrm{~min}^{-1}$ while increasing the temperature from ambient to $723 \mathrm{~K}\left(0.167 \mathrm{~K} \mathrm{~s}^{-1}\right)$ and holding at temperature for up to $2 \mathrm{~h}$.

\subsection{Partial Methane Oxidation}

$\mathrm{Cu}$-CHA samples were first pretreated in He (UHP, Indiana Oxygen, $\left.50 \mathrm{~cm}^{3} \mathrm{~min}^{-1}\right)$ at $723 \mathrm{~K}\left(0.167 \mathrm{~K} \mathrm{~s}^{-1}\right)$ for $2 \mathrm{~h}$ followed by activation in dry air $\left(21 \mathrm{kPa} \mathrm{O}_{2}\right.$, Zero grade air, $50 \mathrm{~cm}^{3}$ $\left.\mathrm{min}^{-1}\right)$ at $723 \mathrm{~K}$ for various times $(0-15 \mathrm{ks})$ and then cooled to ambient temperature in He (Indiana Oxygen, $99.999 \%$, $50 \mathrm{~cm}^{3} \mathrm{~min}^{-1}$ ). Methane (20 kPa, Indiana Oxygen, $99.999 \%$ ) with balance of helium ( $81 \mathrm{kPa}$ ) was introduced and heated to reaction temperature of $473 \mathrm{~K}$ at $0.167 \mathrm{~K} \mathrm{~s}^{-1}$ and held for $0.5 \mathrm{~h}$. Prior to methanol extraction, the system was purged with $\mathrm{He}\left(0.1 \mathrm{~h}, 50 \mathrm{~cm}^{3} \mathrm{~min}^{-1}\right)$ and then the flow was switched to $2.5 \mathrm{kPa} \mathrm{H} 2 \mathrm{O}$ in a $\mathrm{He}$ carrier $\left(30 \mathrm{~cm}^{3} \mathrm{~min}^{-1}\right)$ at $473 \mathrm{~K}$ for 1 h. An online mass selective detector (Agilent, 5973N) was used to quantify methanol $\left(\mathrm{m} / \mathrm{z}^{+}=31\right)$ using $\mathrm{Ar}$ (Indiana Oxygen, $99.999 \%)$ as a calibration standard $\left(\mathrm{m} / \mathrm{z}^{+}=40\right)$, and to monitor potential side products including $\mathrm{CO}, \mathrm{CO}_{2}, \mathrm{CH}_{2} \mathrm{O}$, and $\mathrm{C}_{2} \mathrm{H}_{6} \mathrm{O}\left(\mathrm{m} / \mathrm{z}^{+}=28,44,29,45\right.$, respectively).

\subsection{Density Functional Theory Calculations}

Calculations were performed using the Vienna ab initio Simulation Package (VASP) ${ }^{38}$ version 5.4.4. For all calculations, only considered the $\Gamma$ point was considered when sampling the first Brillouin zone. Periodic spin-polarized DFT $+U$ calculations were performed with a $400 \mathrm{eV}$ cutoff energy, a plane-wave basis, and the PBE functional coupled with a semi-empirical D3 dispersion correction with Becke-Johnson damping ${ }^{39-40}$ on a CHA supercell containing 12 T-sites. Electron-ion interactions were described with projector augmented wave (PAW) ${ }^{41}$ method. For the $+U$ calculations, the $U$ value for the d-orbitals of $\mathrm{Cu}$ was set to 6.0 $\mathrm{eV}$ based on a recent benchmarking study by Chen et al. ${ }^{42}$ Lowest energy $\mathrm{Cu}$ dimer structures were sampled over 150 ps $300 \mathrm{~K}$ ab initio molecular dynamics (AIMD) simulations with NVT ensemble with Nosé-Hoover thermostat.20 Unique local minima for each $\mathrm{Cu}$ dimer motif were identified by optimizing 400 structures (equally spaced in time). The structures were relaxed until all forces were smaller than $0.01 \mathrm{eV} / \AA ̊$, with a convergence criterion of $10^{-8} \mathrm{eV}$ for energies inside self-consistent-field (SCF) cycles. Raman intensity calculations followed the same protocol described by Liang et al. $^{43}$ For $\mathrm{Cu}$ dimer structures with multiple unique local minima, spectra were Boltzmann-averaged to compute the final spectra reported in Figures 3 and S15:

$\langle I\rangle=\frac{\sum_{i} I_{i} e^{-E_{i} / k_{\mathrm{B}} T}}{\sum_{i} e^{-E_{i} / k_{\mathrm{B}} T}}$

where $\langle I\rangle$ is the Boltzmann averaged Raman intensity for a Cu dimer type (e.g., IV), $I_{i}$ is the simulated spectra of the $i^{\text {th }}$ 

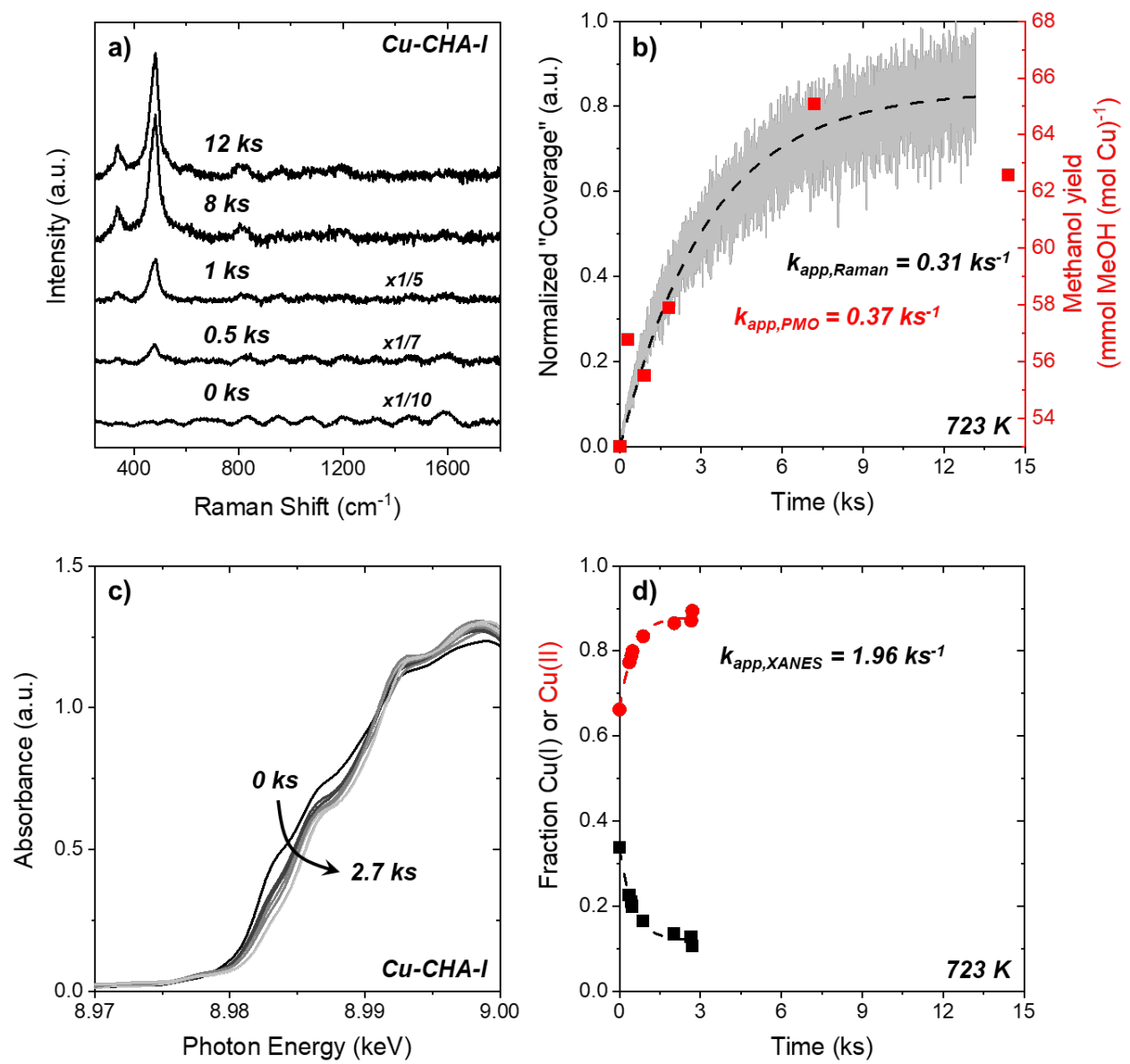

Figure 1. Time-resolved resonance Raman $\left(\lambda_{\mathrm{ex}}=532 \mathrm{~nm}\right)$ and X-ray absorption spectra of Cu-CHA-I during activation within $\mathrm{O}_{2}(21 \mathrm{kPa} \mathrm{O}$, $80 \mathrm{kPa} \mathrm{He}, 723 \mathrm{~K})$. a) Selected Raman spectra of $\mathrm{Cu}-\mathrm{CHA}-\mathrm{I}$ at periodic intervals after introduction of $\mathrm{O}_{2}$, and b) the normalized contribution (i.e., coverage) of the steady-state Raman spectrum obtained through MCR-ALS (gray line, -) together with corresponding methanol yields normalized by the $\mathrm{Cu}$ content (red ) for the Cu-CHA-I sample. c) X-ray absorption spectra of $\mathrm{Cu}$-CHA-I obtained after introduction of $\mathrm{O}_{2}$, and d) the corresponding fraction of $\mathrm{Cu}$ (I) (black $\square$ and $\mathrm{Cu}(\mathrm{II})$ (red -) as a function of time (see Section S5 for fitting procedure). Cu-CHA-I samples were reduced in He at $723 \mathrm{~K}$ for $2 \mathrm{~h}$ prior to the introduction of $\mathrm{O}_{2}$. All spectra in panel a) are vertically offset and scaled by the indicated amount for clarity. The dashed curves in panels b) and d) represent fits to a first-order rate expression to the Raman-derived coverages and XANES-derived $\mathrm{Cu}$ fractions, respectively.

local minimum within that dimer type (e.g., IV-1), $k_{\mathrm{B}}$ is the Boltzmann constant, $E_{i}$ is the energy spectra of the $i^{\text {th }}$ local minimum within that type, and $T$ is the temperature. Figure S15 reports the computed spectra for each $\mathrm{Cu}$ dimer and local minima. All unique local minima structures used to compute frequencies are provided in the SI, Section S7.

\subsection{RESULTS AND DISCUSSION}

3.1 Disparate Timescales for $\mathrm{Cu}$ Oxidation and $\mathrm{Cu}_{\mathrm{x}} \mathrm{O}_{\mathrm{y}}$ Formation Observed via $\mathrm{X}$-ray Absorption and Raman Spectroscopy

The thermodynamics of copper oxidation and reduction depends on $\mathrm{Cu}$ site speciation, and in turn, the zeolite composition and framework $\mathrm{Al}$ arrangement, as shown by the DFT-derived phase diagrams reported by Paolucci et al. ${ }^{7}$ All $\mathrm{Cu}$ ions at 6-MR paired sites are in their $\mathrm{Cu}(\mathrm{II})$ states at $723 \mathrm{~K}\left(21 \mathrm{kPa} \mathrm{O}_{2}\right)$, while $\mathrm{Cu}$ ions at 6-MR isolated $\mathrm{Al}$ sites may reside as mixtures of $\mathrm{Cu}(\mathrm{II})$ and $\mathrm{Cu}(\mathrm{I})$ states at $723 \mathrm{~K}$ $\left(21 \mathrm{kPa} \mathrm{O}_{2}\right.$ ). The $\mathrm{Cu}$ speciation also influences observed auto-reduction behavior at $673 \mathrm{~K}\left(1 \mathrm{~Pa} \mathrm{O}_{2}\right.$ in balance $\left.\mathrm{He}\right)$, as $\mathrm{Z}_{2} \mathrm{Cu}$ sites remain $\mathrm{Cu}(\mathrm{II})$ while $\mathrm{ZCuOH}$ sites thermodynamically prefer the $\mathrm{Cu}(\mathrm{I})$ state. ${ }^{14}$ Elementary steps to complete $\mathrm{ZCuOH}$ auto-reduction events likely require two $[\mathrm{CuOH}]^{+}$within close enough proximity to form binuclear $\mathrm{Cu}$-oxo species, ${ }^{44}$ which suggests that spatially distant $\mathrm{ZCuOH}$ sites will not auto-reduce. ${ }^{14}$ This interpretation is consistent with Raman spectra $\left(\lambda_{\mathrm{ex}}=532 \mathrm{~nm}, 18,800\right.$ $\mathrm{cm}^{-1}$ ) collected in He at $723 \mathrm{~K}$ that do not show discernible features for binuclear $\mathrm{Cu}$-oxo structures, (Figure 1a; spectrum at 0 ks solely reflects background fluorescence), which if formed presumably have auto-reduced.

The Cu-CHA samples studied here will be referred to as Cu-CHA-I, Cu-CHA-P or Cu-CHA-M where I, P, and M contain $\mathrm{Cu}$ exchanged at predominantly 6-MR isolated $\mathrm{Al}$ sites, 6$\mathrm{MR}$ paired $\mathrm{Al}$ sites, or mixtures thereof, respectively. All $\mathrm{Cu}-$ CHA samples exhibit UV-Vis absorption features between 8,000 and $20,000 \mathrm{~cm}^{-1}$ after $\mathrm{O}_{2}$ activation at $723 \mathrm{~K}$ (Figures S3 - S5), which are consistent with the $\mathrm{Cu}$ speciation expected within $\mathrm{Cu}-\mathrm{CHA}$ materials that contain predominantly $\mathrm{ZCuOH}$ sites, $\mathrm{Z}_{2} \mathrm{Cu}$, or mixtures thereof. ${ }^{20}$

Figure 1a shows in situ resonance Raman spectra of $\mathrm{Cu}-$ CHA-I during $\mathrm{O}_{2}$ activation, demonstrating that more than 7 
ks $(\sim 2 \mathrm{~h})$ at $723 \mathrm{~K}$ is required for $\mathrm{Cu}_{\mathrm{x}} \mathrm{O}_{\mathrm{y}}$ to reach their steady-state structures. These spectra were obtained with an excitation wavelength of $532 \mathrm{~nm}$ to achieve resonance Raman spectra. To capture the transient changes in the number of Raman-active species, we continuously collect Raman spectra during $\mathrm{O}_{2}$ activation. Multivariate curve resolution-alternating least squares (MCR-ALS) analysis allows us to recover the changes in spectral contributions over time from each kinetically and spectroscopically distinguishable species. ${ }^{37,45}$ For each sample, we find that a single component (i.e., spectrum) and concentration profile describes the time-resolved measurements. If two or more components are modeled, the additional spectra resemble changes within the spectral baseline or random fluctuations in the measurements (See Section S8) and do not contain features consistent with reported $\mathrm{Cu}_{\mathrm{x}} \mathrm{O}_{\mathrm{y}}$ complexes (vide infra) or the CHA framework.

During $\mathrm{O}_{2}$ activation treatments at $723 \mathrm{~K}\left(21 \mathrm{kPa} \mathrm{O}_{2}, 80\right.$ $\mathrm{kPa} \mathrm{He}$ ), the formation of Raman-active $\mathrm{Cu}_{\mathrm{x}} \mathrm{O}_{\mathrm{y}}$ species occurs over a period of 12 ks (Figure 1b), while the near-complete oxidation of $\mathrm{Cu}(\mathrm{I})$ to $\mathrm{Cu}(\mathrm{II})$ approaches a steady-state within $1 \mathrm{ks}$ as monitored by X-ray absorption near edge spectroscopy (XANES; Figure 1d). In both cases, the rate $\left(r_{a p p}\right)$ of $\mathrm{O}_{2}$ activation (Raman) and $\mathrm{Cu}(\mathrm{I})$ oxidation (XANES) follows pseudo-first order kinetics:

$$
r_{a p p}=k_{a p p}[C u(I)]
$$

where $k_{\text {app }}$ is the apparent rate constant and $[\mathrm{Cu}(\mathrm{I})]$ is the molar density of $\mathrm{Cu}(\mathrm{I})$ ions in the $\mathrm{Cu}$-CHA sample. Within $\mathrm{Cu}-\mathrm{CHA}-\mathrm{I}$, the rate constant for $\mathrm{Cu}(\mathrm{I})$ oxidation $\left(k_{\text {app }, X A N E S}=\right.$ $1.96 \mathrm{ks}^{-1}$ ) is 6-times greater than the rate constant to form the $\mathrm{Cu}_{\mathrm{x}} \mathrm{O}_{\mathrm{y}}$ species observed by Raman spectroscopy ( $k_{a p p, R a}$ $\left.\operatorname{man}=0.31 \mathrm{ks}^{-1}\right)$. Similarly, the rate constants for $\mathrm{Cu}(\mathrm{I})$ oxidation within Cu-CHA-M (Figure S14; $k_{\text {app,XANES }}=4.01 \mathrm{ks}^{-1}$ ) are 40-fold greater than rate constant obtained from transients measured by Raman $\left(k_{a p p, R a m a n}=0.10 \mathrm{ks}^{-1}\right)$. In situ EXAFS after $1 \mathrm{ks}$ reveal that $\mathrm{Cu}$ sites in $\mathrm{Cu}-\mathrm{CHA}-\mathrm{M}$ (Table S6) and $\mathrm{Cu}-$ CHA-I (Table S4) are three-coordinate. These spectral features are distinct from those observed in Raman (Figure 2) and EXAFS (four-coordinate $\mathrm{Cu}$; Table S5) of $\mathrm{Cu}-\mathrm{CHA}-\mathrm{P}$ that contain predominantly $\mathrm{Cu}(\mathrm{II})$ before and after contact with $\mathrm{O}_{2}$ (Figure $\mathrm{S} 11$ ) as expected for $\mathrm{Z}_{2} \mathrm{Cu}$ sites that are PMOinactive.

Importantly, the yields of $\mathrm{CH}_{3} \mathrm{OH}$ (per mol of $\mathrm{Cu}$ ) increase monotonically from 0 to $\sim 10$ ks over $\mathrm{Cu}-\mathrm{CHA}-\mathrm{I}$ (Figure $1 \mathrm{~b}$ ), and $k_{a p p}$ values measured via Raman $\left(0.31 \mathrm{ks}^{-1}\right)$ and PMO $\left(0.37 \mathrm{ks}^{-1}\right)$ are in close agreement, suggesting that the features within these Raman spectra reflect PMO-relevant active sites proposed previously to be binuclear $\mathrm{Cu}$-oxo site types that require longer timescales to form. ${ }^{14,16,18,22}$ A nonnegligible amount of methanol forms on $\mathrm{Cu}$-CHA-I following a pretreatment in helium (Figure $1 \mathrm{~b}$; zero $\mathrm{O}_{2}$ activation time) followed by exposure to methane. The formation of methanol without an intentional oxidative treatment was also observed by Pappas et al. on $\mathrm{Cu}$-CHA and ascribed to a small fraction of $\mathrm{Cu}$ remaining as $\mathrm{Cu}(\mathrm{II})$ in multinuclear $\mathrm{Cu}_{\mathrm{x}} \mathrm{O}_{\mathrm{y}}$ structures that do not auto-reduce and are thus able to activate methane. ${ }^{14}$ Brezicki et al. reported similar findings for Cu-MOR and instead attributed this to trace oxygen impurities in the sample or reaction apparatus. ${ }^{17} \mathrm{We}$ cannot exclude the possibility that minority $\mathrm{Cu}_{\mathrm{x}} \mathrm{O}_{\mathrm{y}}$ species are present that do not auto-reduce and subsequently activate methane, or the possibility of trace oxygen impurities as the reason for non-zero methanol yields observed without intentional oxidative treatments. We can, however, definitively conclude that methanol yields increase with longer $\mathrm{O}_{2}$ activation times $(>2 \mathrm{~h})$ due to the formation of the $\mathrm{Cu}_{\mathrm{x}} \mathrm{O}_{\mathrm{y}}$ structure probed via Raman spectroscopy.

These comparisons demonstrate three critical points with broad significance for stoichiometric and catalytic oxidation reactions performed over $\mathrm{Cu}$ exchanged zeolites. First, $\mathrm{Cu}$ ions oxidize quickly to form $\mathrm{Cu}(\mathrm{II})$ and the majority of $\mathrm{Cu}$ exists as $\mathrm{Cu}$ (II) within $2 \mathrm{ks}$. Consequently, the $\mathrm{Cu}_{\mathrm{x}} \mathrm{O}_{\mathrm{y}}$ species responsible for the Raman scattering features (Figure 1a) must correspond to a Cu(II) complex. Second, changes observed by Raman over longer timescales suggest that following a rapid oxidation of $\mathrm{Cu}(\mathrm{I})$ to $\mathrm{Cu}(\mathrm{II})$ the structure of the $\mathrm{Cu}$ complexes continue to evolve through subsequent processes that occur at slower rates to form the Raman active $\mathrm{Cu}_{\mathrm{x}} \mathrm{O}_{\mathrm{y}}$ species. Third, yields of $\mathrm{CH}_{3} \mathrm{OH}$ formed by PMO continue to increase well after the $\mathrm{Cu}(\mathrm{I})$ to $\mathrm{Cu}(\mathrm{II})$ transition period and correlate strongly with the numbers of the Raman-resonant $\mathrm{Cu}_{\mathrm{x}} \mathrm{O}_{\mathrm{y}}$ complexes, which suggests this $\mathrm{Cu}_{\mathrm{x}} \mathrm{O}_{\mathrm{y}}$ species are linked to the active intermediates responsible for partial methane oxidation.

\subsection{Identity of Raman-Active $\mathrm{Cu}_{\mathrm{x}} \mathrm{O}_{\mathrm{y}}$ Species Formed Over ZCuOH}

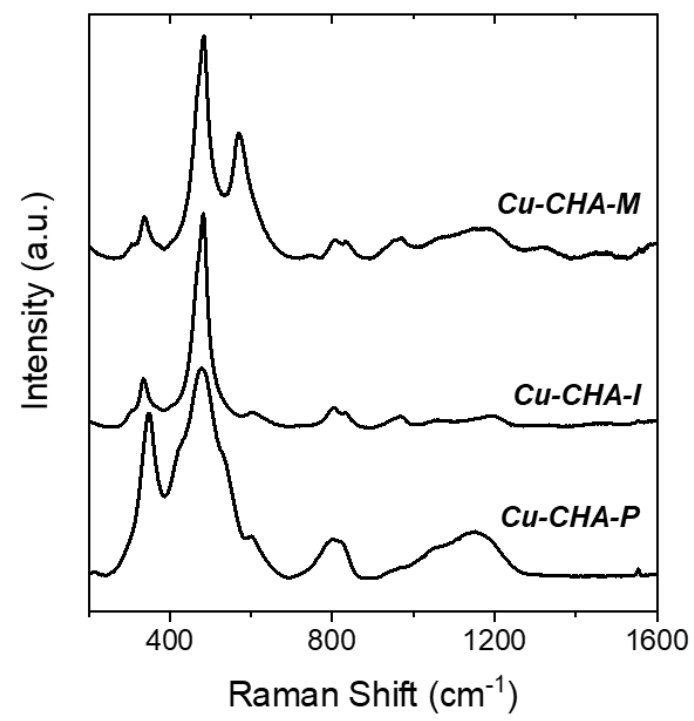

Figure 2. In situ steady-state Raman spectra $\left(\lambda_{\text {ex }}=532 \mathrm{~nm}\right)$ of $\mathrm{Cu}$-CHA samples containing predominantly $\mathrm{Z}_{2} \mathrm{Cu}$ sites (Cu-CHA-P), ZCuOH sites (Cu-CHA-I), or mixtures thereof (Cu-CHA-M) after $\mathrm{O}_{2}$ activation $(21 \mathrm{kPa} \mathrm{O}, 80 \mathrm{kPa} \mathrm{He}, 723$ $\mathrm{K})$. Samples were pretreated in He at $723 \mathrm{~K}$ for $2 \mathrm{~h}$ prior to the introduction of $\mathrm{O}_{2}$. All spectra have been normalized to the most-intense feature $\left(\sim 450 \mathrm{~cm}^{-1}\right)$ and are vertically offset for clarity.

The identity of the PMO- and Raman-active $\mathrm{Cu}_{\mathrm{x}} \mathrm{O}_{\mathrm{y}}$ species must be determined to generate a meaningful model that describes its genesis during $\mathrm{O}_{2}$ activation. Figure 2 shows steady-state spectra contain several significant vibrational features between $300-1,300 \mathrm{~cm}^{-1}$. The sharp features at 330 and $475 \mathrm{~cm}^{-1}$ correspond to the $v(\mathrm{~T}-0-\mathrm{T})$ mode of the 

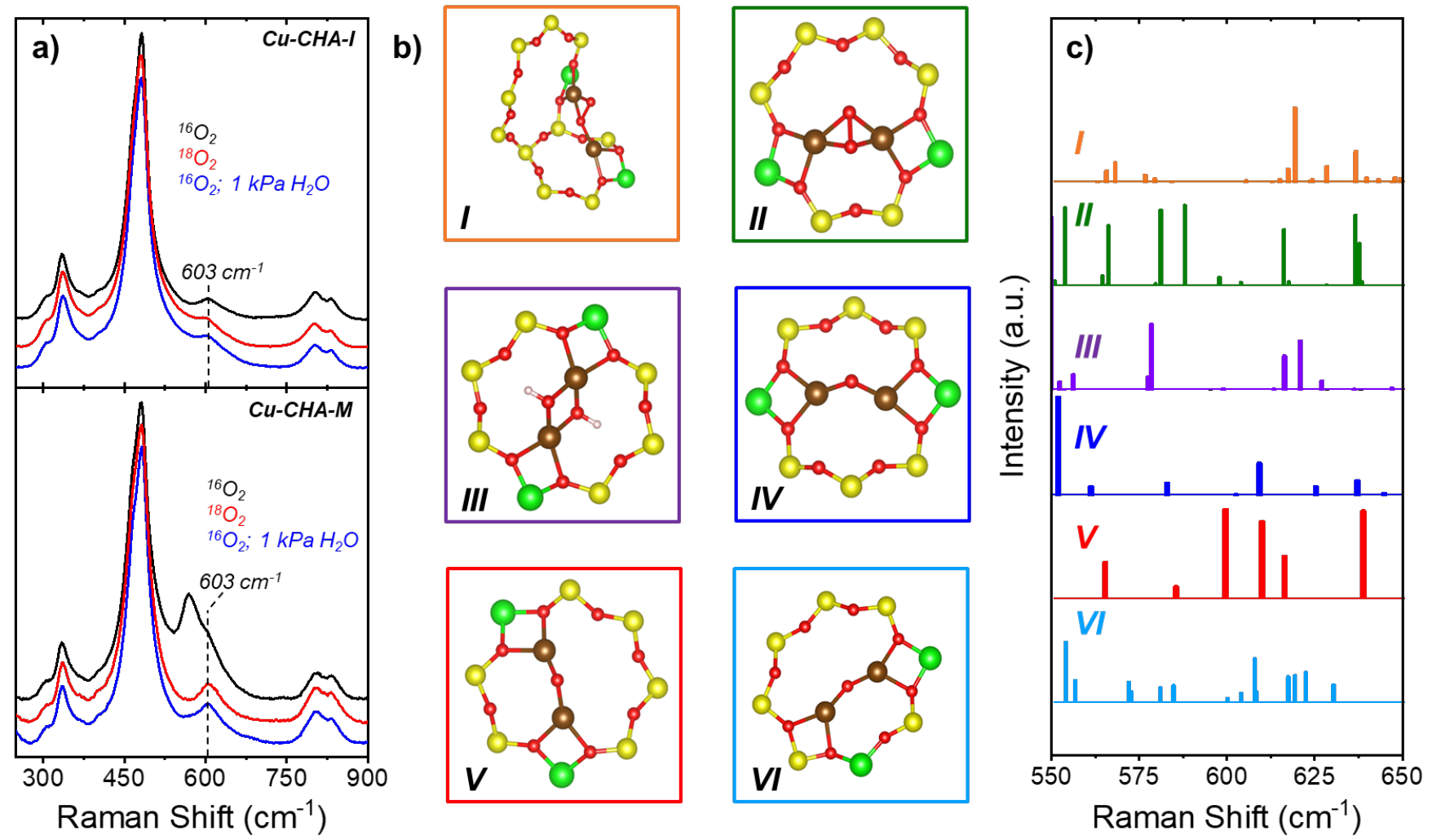

Figure 3. In situ steady-state Raman spectra ( $\left.\lambda_{\mathrm{ex}}=532 \mathrm{~nm}\right)$ of $\mathrm{Cu}-\mathrm{CHA}-\mathrm{I}(\mathrm{top})$ and Cu-CHA-M (bottom) after $\mathrm{O}_{2}$ activation $(21$ $\mathrm{kPa} \mathrm{O}, 80 \mathrm{kPa} \mathrm{He}, 723 \mathrm{~K}$ ) with natural abundance ${ }^{16} \mathrm{O}_{2}$ (black), ${ }^{18} \mathrm{O}_{2}$ (red), or ${ }^{16} \mathrm{O}_{2}$ with $1 \mathrm{kPa}$ of $\mathrm{H}_{2} \mathrm{O}$ (blue). b) Optimized geometries of $\mathrm{Cu}$ dimers I (orange, trans-peroxo dicopper), II (green, $\mu$ - $\left(\eta^{2}: \eta^{2}\right)$ peroxo dicopper), III (purple, bis( $\mu$-hydroxyl) dicopper), IV (blue, mono- $\mu$-oxo dicopper), $\mathrm{V}$ (red, mono- $\mu$-oxo dicopper), and VI (teal, mono- $\mu$-oxo dicopper), where dicopper species IV, V, and VI differ in the arrangement of $\mathrm{Al}$ atoms within the 8-membered ring. c) The corresponding simulated Raman-active vibrations for each of the $\mathrm{Cu}$ dimers and monomers. Colors within panel c) are consistent with the colored boxes for each $\mathrm{Cu}$ dimer in b).

six-membered rings and $v_{s}(\mathrm{~T}-0-\mathrm{T})$, respectively. ${ }^{46-47}$ The broad features centered around $800 \mathrm{~cm}^{-1}$ and $1100 \mathrm{~cm}^{-1}$ correspond to $v_{\mathrm{s}}(\mathrm{Si}-\mathrm{O})$ and $v_{\text {as }}(\mathrm{Si}-\mathrm{O})$ modes, which are typical of zeolite frameworks. ${ }^{46-47}$ The features at 580 (observed only for $\mathrm{Cu}-\mathrm{CHA}-\mathrm{M})$ and $603 \mathrm{~cm}^{-1}$ have previously been assigned as $v(\mathrm{Cu}-0)$ of a trans- $\mu$-1,2-peroxo dicopper(II) intermediate and $v(\mathrm{Cu}-\mathrm{O})$ of a mono-( $\mu$-oxo)dicopper(II) species, respectively. ${ }^{22}$ Figure 2 also displays a spectrum of $\mathrm{Cu}$ CHA-P, intended as a control material to contain predominantly $\mathrm{Z}_{2} \mathrm{Cu}$ sites that have been reported previously to be PMO-inactive $^{14}$ and thus, should not form multinuclear $\mathrm{Cu}_{\mathrm{x}} \mathrm{O}_{\mathrm{y}}$ species during $\mathrm{O}_{2}$ activation. Figure 2 shows that the Raman spectrum of $\mathrm{O}_{2}$-activated $\mathrm{Cu}$-CHA-P possesses a spectral lineshape distinct from $\mathrm{Cu}-\mathrm{CHA}-\mathrm{I}$ and $\mathrm{Cu}-\mathrm{CHA}-\mathrm{M}$, which suggests that Raman-active species that form on $\mathrm{Cu}$ CHA-P is not the same as the PMO-active species formed on the $\mathrm{ZCuOH}$-containing materials. In the presence of $\mathrm{H}_{2} \mathrm{O}(0.1$ $-1 \mathrm{kPa} \mathrm{H}_{2} \mathrm{O}, 21 \mathrm{kPa} \mathrm{O}_{2}, 723 \mathrm{~K}$, Figure $3 \mathrm{~A}$ ), spectra of $\mathrm{Cu}-\mathrm{CHA}-$ $M$ show attenuation of the large vibrational feature at 580 $\mathrm{cm}^{-1}$ such that these spectra closely resemble those of $\mathrm{Cu}$ CHA-I.

The identity of the species observed during $\mathrm{O}_{2}$ activation by Raman spectroscopy was evinced through a combination of isotopic labeling and computed Raman spectra of plausible chemical species. Isotopic labeling experiments with
${ }^{18} \mathrm{O}_{2}$ were performed by treating $\mathrm{Cu}-\mathrm{CHA}-\mathrm{I}$ and $\mathrm{Cu}-\mathrm{CHA}-\mathrm{M}$ at $723 \mathrm{~K}$ in flowing ${ }^{18} \mathrm{O}_{2}\left(21 \mathrm{kPa}{ }^{18} \mathrm{O}_{2}, 80 \mathrm{kPa} \mathrm{He}\right)$ to identify vibrational shifts to aid in the identification of reactive $\mathrm{Cu}_{\mathrm{x}} \mathrm{O}_{\mathrm{y}}$ species formed. Both $\mathrm{Cu}-\mathrm{CHA}-\mathrm{I}$ and $\mathrm{Cu}-\mathrm{CHA}-\mathrm{M}$ possess Raman scattering features at $603 \mathrm{~cm}^{-1}$ when either ${ }^{18} \mathrm{O}_{2}$ or ${ }^{16} \mathrm{O}_{2}$ is used (Figure 3). Cu-CHA-M activated in $\mathrm{O}_{2}$ under dry conditions, however, possesses an additional feature around $580 \mathrm{~cm}^{-1}$ previously attributed to trans- $\mu-1,2-$ peroxo dicopper(II). ${ }^{22}$ Consequently, these data suggest that the presence of $\mathrm{H}_{2} \mathrm{O}$ deliberately added to ${ }^{16} \mathrm{O}_{2}$ or present in trace amounts within ${ }^{18} \mathrm{O}_{2}$ aid in the structural conversion of trans- $\mu$-1,2-peroxo dicopper(II) to form the species that exhibits a Raman scattering at $603 \mathrm{~cm}^{-1}$. Notably, these findings differ from those of Lobo and coworkers, who observed an isotopic shift $\left(\Delta^{18} \mathrm{O}_{2}\right)$ of $24 \mathrm{~cm}^{-1}$ for the vibration at $603 \mathrm{~cm}^{-1} .22$ In their work, a scattering feature at 836 $\mathrm{cm}^{-1}$ was assigned to $v(0-0)$ of trans- $\mu-1,2$-peroxo dicopper. ${ }^{22}$ Here, the lack of shift in the Raman spectra of ${ }^{18} \mathrm{O}_{2}$ activated $\mathrm{Cu}$-CHA zeolites seems to exclude this possibility. Consequently, the broad features centered around 800 and $1100 \mathrm{~cm}^{-1}$ (Figure 2) appear to reflect framework $v_{\mathrm{s}}(\mathrm{Si}-\mathrm{O})$ and $v_{\text {as }}(\mathrm{Si}-\mathrm{O})$ modes that are strongly scattered based upon preferential excitation (i.e., resonance) of $\mathrm{Cu}_{x} \mathrm{O}_{y}$ species they stabilize. 
To aid in spectral assignments, we used DFT $+U$ to model frequently discussed $\mathrm{Cu}$ dimer structures (Figure $3 \mathrm{~b}$ ) and calculate their Raman spectra (Figure $3 c) .{ }^{20}$ For each
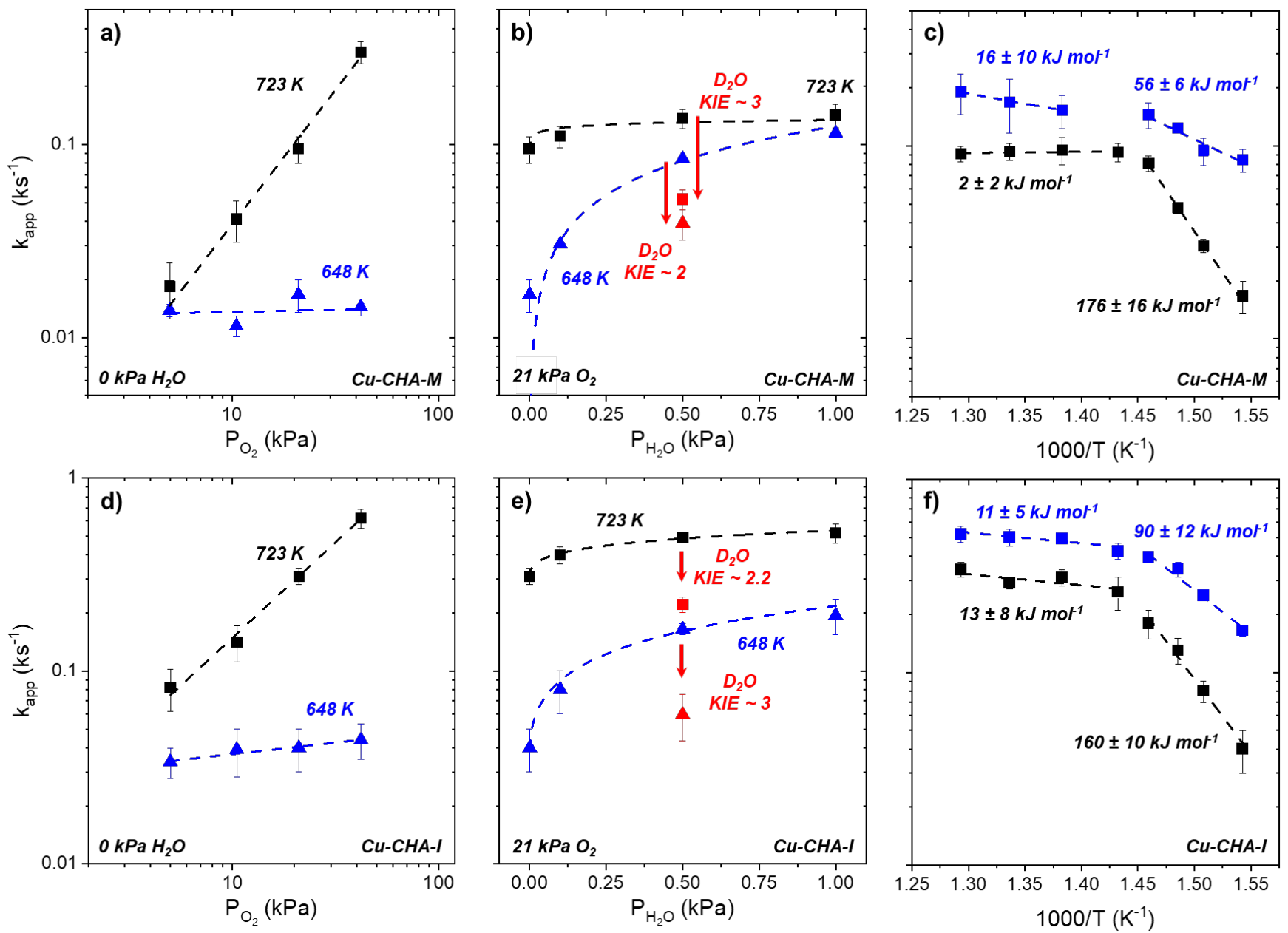

Figure 4. Apparent rate constants $\left(k_{\text {app }}\right)$ for ZCuOCuZ formation over Cu-CHA-M (panels a, b and c) and Cu-CHA-I (panels d, e, and f) as function of a, d) $P_{\mathrm{O}_{2}}\left(0 \mathrm{kPa} \mathrm{H} \mathrm{H}_{2} \mathrm{O}\right)$; b, e) $P_{\mathrm{H}_{2} \mathrm{O}}\left(21 \mathrm{kPa} \mathrm{O}_{2}\right)$ at $723 \mathrm{~K}(\boldsymbol{\square})$ and $648 \mathrm{~K}(\boldsymbol{\Delta})$; and c, f) inverse temperature with water vapor $\left(\boldsymbol{\Delta}, 0.5 \mathrm{kPa} \mathrm{H}_{2} \mathrm{O}, 21 \mathrm{kPa} \mathrm{O_{2 }}\right)$ or in the absence of water $\left(\mathbf{\square}, 0 \mathrm{kPa} \mathrm{H}_{2} \mathrm{O}, 21 \mathrm{kPa} \mathrm{O}_{2}\right)$. All samples were pretreated $\left(101 \mathrm{kPa} \mathrm{He}, 723 \mathrm{~K}, 2 \mathrm{~h}\right.$ ) prior to introducing $\mathrm{O}_{2}$. Dashed curves in panels a, b, d, and e represent power-law fits, while those in panels $\mathrm{c}$ and $\mathrm{f}$ are fits of the Arrhenius equation. Values listed within panels $\mathrm{c}$ and f correspond to the apparent activation energies within the different kinetic regimes, obtained through fits of the Arrhenius equation.

optimized structure, the change in polarizability was calculated along the normal modes of the simulated vibrations to determine the frequencies of Raman-active vibrations (see Section 2.4 for full details). ${ }^{48}$ The precise assignment of a complex whose calculated molecular vibrations describe the Raman features in Figures 1 and 3a (i.e., at $603 \mathrm{~cm}^{-1}$ ) requires that several criteria be met. First, the $\mathrm{Cu}_{\mathrm{x}} \mathrm{O}_{\mathrm{y}}$ complex must exist as $\mathrm{Cu}(\mathrm{II})$, which excludes the possibility of bis- $\mu-$ oxo dicopper and trimeric $\mathrm{Cu}$-oxo complexes. ${ }^{27,}{ }^{29} \mathrm{Second}$, the $\mathrm{Cu}_{\mathrm{x}} \mathrm{O}_{\mathrm{y}}$ intermediate must absorb $532 \mathrm{~nm}\left(18,800 \mathrm{~cm}^{-1}\right.$; Figures S3 and S5) light to provide the resonance Raman effect. Third, the candidate dimer structures modeled must possess Raman scattering features within $20 \mathrm{~cm}^{-1}$ of the experimentally measured vibrations, which is the range of deviations between experimental and theoretical frequencies commonly reported for similar materials. ${ }^{49-50}$ Fourth, the simulated vibration near $603 \mathrm{~cm}^{-1}$ must not contain significant $\mathrm{Cu}-\mathrm{O}$ or $\mathrm{O}-\mathrm{O}$ bond deformations (e.g., stretching modes of superoxo or peroxo complexes), as these vibrations would produce a significant $\Delta^{18} \mathrm{O}_{2}$.

Among the complexes depicted in Figure $3 \mathrm{~b}$, mono( $\mu$ oxo) dimer species (IV, V, and VI) most closely satisfy these criteria. These complexes exhibit strong absorbance between $8,000-20,000 \mathrm{~cm}^{-1}$ correspond to d-d transitions. ${ }^{20}$ Frequency calculations show that these species also possess a significant Raman scattering features between $590-620$ $\mathrm{cm}^{-1}$ that do not show significant deformation of the $\mathrm{Cu}-\mathrm{O}$ bonds (Supporting Information, Videos). In comparison, our calculations ${ }^{20}$ show that $\mathrm{Cu}$ dimers I - III (Figure $3 \mathrm{~b}$ ) do not have significant UV-Vis absorbance features near $18,800 \mathrm{~cm}^{-1}$ and do not possess Raman features near 603 $\mathrm{cm}^{-1}$ that correspond to vibrations with significant $\mathrm{Cu}-\mathrm{O}$ or 0-0 bond deformations (which is inconsistent with $\Delta^{18} \mathrm{O}_{2}=$ $0)$. Consequently, the $\mathrm{Cu}_{\mathrm{x}} \mathrm{O}_{\mathrm{y}}$ species that form over $\mathrm{Cu}-\mathrm{CHA}$ I and $\mathrm{Cu}-\mathrm{CHA}-\mathrm{M}$ over long time scales ( 0 - $15 \mathrm{ks})$ are active for PMO and that are responsible for the $603 \mathrm{~cm}^{-1}$ feature 
likely correspond to mono( $\mu$-oxo)dicopper intermediates. We note, however, that the precise and unambiguous assignment of the $603 \mathrm{~cm}^{-1}$ Raman scattering feature to a multinuclear vibration of mono( $\mu$-oxo)dicopper species remains difficult as DFT $+U$ calculations are performed off-resonance and do not account for the preferential excitation of vibrations due to induced electronic transitions. Consequently, we tentatively assign the species responsible for the observed Raman feature at $603 \mathrm{~cm}^{-1}$ and for PMO reactivity as a mono( $\mu$-oxo)dicopper species but do not exclude any of the plausible isomers (species IV, V, or VI). For brevity, we refer to mono( $\mu$-oxo)dicopper as $\mathrm{ZCuOCuZ}$ in the following sections.

\subsection{Mechanistic Interpretations of Mean-Field $\mathrm{O}_{2}$ Acti- vation Kinetics}

Observations presented earlier in this report suggest that rates of $\mathrm{ZCuOCuZ}$ formation over $\mathrm{Cu}(\mathrm{I})$ ions likely depend on $\mathrm{O}_{2}$ and $\mathrm{H}_{2} \mathrm{O}$ pressure with a functional form resembling

$$
r_{A p p}=k_{f o r m} P_{O_{2}}^{a} P_{H_{2} O}^{b}[C u(I)]
$$

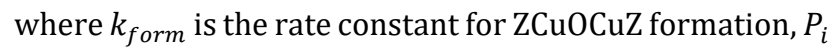
is the partial pressure of species $i, a$ and $b$ represent the power-law dependence of rates on $P_{\mathrm{O}_{2}}$ and $P_{\mathrm{H}_{2} \mathrm{O}}$, respectively, and $[\mathrm{Cu}(\mathrm{I})]$ is the number of $\mathrm{Cu}(\mathrm{I})$ species. The conversions of $\mathrm{O}_{2}$ and $\mathrm{H}_{2} \mathrm{O}$ remain differential $(<1 \%)$ throughout the formation of $\mathrm{ZCuOCuZ}$ complexes, because these reactants are introduced with molar flowrates that greatly exceed the consumption of $\mathrm{Cu}(\mathrm{I})$ ions within the sample over the relevant timescales for ZCuOCuZ formation $(1-150$ $\mathrm{ks}) .{ }^{51}$ As such, the rate of $\mathrm{ZCuOCuZ}$ formation can be stated in a form that reflects a pseudo-first-order dependence on $[\mathrm{Cu}(\mathrm{I})]$

$$
r_{A p p}=k_{a p p}[C u(I)]
$$

where $k_{a p p}$ is the apparent rate constant for ZCuOCuZ formation and implicitly contains the dependence of $\mathrm{O}_{2}$ activation rates on $P_{\mathrm{O}_{2}}$ and $\mathrm{P}_{\mathrm{H}_{2} \mathrm{O}}$.

Figures $4 \mathrm{c}$ and $4 \mathrm{f}$ show that values of $k_{a p p}$ over $\mathrm{Cu}-\mathrm{CHA}-\mathrm{I}$ and $\mathrm{Cu}-\mathrm{CHA}-\mathrm{M}$ samples exhibit two distinct kinetic regimes at low $(648-673 \mathrm{~K})$ and high $(685-773 \mathrm{~K})$ temperature. The Cu-CHA-P control sample prepared to contain predominantly $\mathrm{Z}_{2} \mathrm{Cu}$ sites was omitted from this analysis because this sample does not facilitate PMO. At low temperatures, rates of $\mathrm{ZCuOCuZ}$ formation do not depend on $P_{\mathrm{O}_{2}}$, exhibit saturation kinetics (i.e., a first-to-zeroth order transition) in $P_{\mathrm{H}_{2} \mathrm{O}}$, and increase exponentially with temperature under either dry conditions $\left(E_{a}=176 \pm 16 \mathrm{~kJ} \mathrm{~mol}^{-1}\right)$ or with $0.5 \mathrm{kPa}$ $\mathrm{H}_{2} \mathrm{O}$ present $\left(E_{a}=56 \pm 6 \mathrm{~kJ} \mathrm{~mol}^{-1}\right)$. In contrast, at high temperatures, $\mathrm{ZCuOCuZ}$ formation rates depend linearly on $P_{\mathrm{O}_{2}}$, remain nearly constant at all $P_{\mathrm{H}_{2} \mathrm{O}}$, and present negligible temperature dependence (i.e., are nearly barrierless). Moreover, ZCuOCuZ formation rates exhibit a normal kinetic isotope effect $\left(k_{a p p, H} / k_{a p p, D}=2-3.2,21 \mathrm{kPa} \mathrm{O}_{2}, 0.5\right.$ $\mathrm{kPa} \mathrm{H}_{2} \mathrm{O}$ or $\mathrm{D}_{2} \mathrm{O}$ ) at both 648 and $723 \mathrm{~K}$, which in conjunction with the functional dependence of formation rates on $P_{\mathrm{H}_{2} \mathrm{O}}$, suggests that $\mathrm{H}_{2} \mathrm{O}$ participates in the activation of $\mathrm{O}_{2}$. Comparisons between rate dependences for $\mathrm{ZCuOCuZ} \mathrm{for-}$ mation at low $(<673 \mathrm{~K})$ and high $(>685 \mathrm{~K})$ temperatures suggest that $\mathrm{Cu}$ ions are saturated with $\mathrm{O}_{2}$-derived intermediates at low temperatures, while $\mathrm{Cu}$ sites are not occupied by an $\mathrm{O}_{2}$-derived species at high temperatures. $\mathrm{ZCuOCuZ}$ formation rates depend similarly on reactant pressures, temperature, and the isotopologue of water used for both $\mathrm{Cu}-\mathrm{CHA}-\mathrm{I}$ and $\mathrm{Cu}-\mathrm{CHA}-\mathrm{M}$ samples, which strongly suggests that the kinetically competent species probed via Raman spectroscopy within these samples are the same (i.e., corresponding to $\mathrm{ZCuOCuZ}$ formation from $\mathrm{ZCu}^{+}$species).

Scheme 1. A series of plausible chemical transformations that describe $\mathrm{ZCuOH}$ reduction and $\mathrm{O}_{2}$ activation to form $\mathrm{ZCuOCuZ}$ species. Z denotes a framework Al atom. Step 3 represents $\mathrm{ZCuOH}$ auto-reduction and is described by two hypothetical steps (steps $3 \mathrm{a}$ and $3 \mathrm{~b}$ ). The $\left[\mathrm{H}_{2} \mathrm{O}\right]$ within step 6 represents the catalytic role of $\mathrm{H}_{2} \mathrm{O}$ in $0-0$ bond dissociation. ZCuOCuZ represents the Raman-active intermediate, and $\mathrm{a}^{\wedge}$ atop an arrow denotes a kinetically-relevant step.

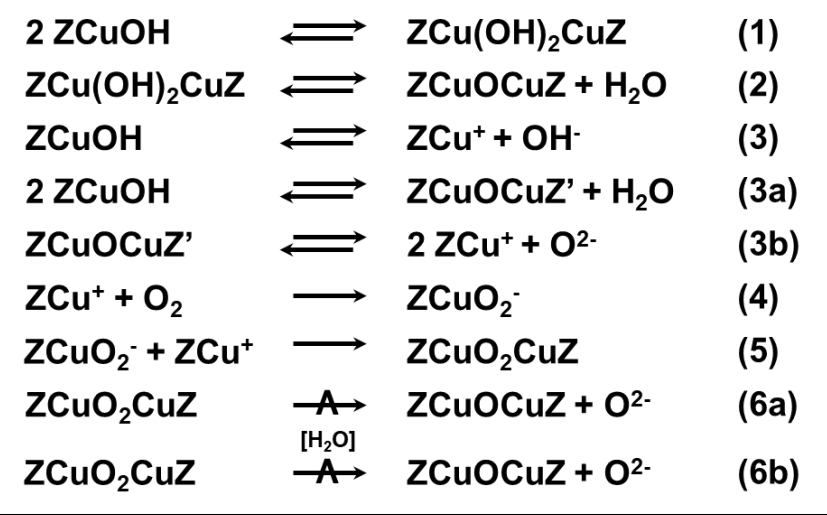

Scheme 1 shows a plausible series of chemical transformations that describe the formation of $\mathrm{ZCuOCuZ}$ species upon contact between $\mathrm{O}_{2}$ and $\mathrm{Cu}(\mathrm{I})$ ions within $\mathrm{Cu}-\mathrm{CHA}$ materials. Two $\mathrm{ZCuOH}$ moieties react to form a bis( $\mu$-hydroxyl)dicopper species $\left(\mathrm{ZCu}(\mathrm{OH})_{2} \mathrm{CuZ}\right.$; step 1), which then dehydrates to form ZCuOCuZ species (step 2). Alternatively, treatments in He (or $\mathrm{CO}$, vide infra) auto-reduce some fraction of $\mathrm{ZCuOH}$ sites to form $\mathrm{ZCu}^{+}$sites (step 3) ${ }^{14,20,44}$ that subsequently oxidize by chemisorbing molecular $\mathrm{O}_{2}$ to form $\mathrm{ZCuO}_{2}$ - intermediates (step 4). Reaction between $\mathrm{ZCuO}_{2}{ }^{-}$and a proximate $\mathrm{ZCu}^{+}$forms a bridging dicopper peroxide complex $\left(\mathrm{ZCuO}_{2} \mathrm{CuZ}\right.$; step 5). ${ }^{52}$ These $\mathrm{ZCuO}_{2} \mathrm{CuZ}$ species may be active intermediates for PMO or may undergo $0-0$ bond cleavage in the absence (step 6a) or presence of $\mathrm{H}_{2} \mathrm{O}$ (step $6 \mathrm{~b}$ ) to form $\mathrm{ZCuOCuZ}$ and release an equivalent of $\mathrm{O}^{2-}$. These $\mathrm{ZCuOCuZ} \mathrm{complexes} \mathrm{appear} \mathrm{to} \mathrm{form} \mathrm{irreversibly,} \mathrm{because}$ the Raman features attributed to this species $\left(580 \mathrm{~cm}^{-1}\right)$ persist for hours under flowing $\mathrm{He}$ after activation with $\mathrm{O}_{2}$, in agreement with previous reports. ${ }^{22}$ Considering the processes described by Scheme 1, the rapid oxidation of $\mathrm{Cu}(\mathrm{I})$ to $\mathrm{Cu}$ (II) observed by XAS (Figure 1d) likely corresponds to step 4 or step 5.

To examine whether auto-reduction (steps 1 - 3, Scheme 1) possibly contributes to the formation of $\mathrm{ZCuOCuZ}$, we investigated the influence of different reductive pretreatments of $\mathrm{ZCuOH}$ sites. Auto-reduction treatments of $\mathrm{ZCuOH}$ species in $\mathrm{He}$ at $723 \mathrm{~K}$ do not fully reduce all $\mathrm{Cu}(\mathrm{II})$ complexes present to $\mathrm{Cu}(\mathrm{I})$ (Figure 1). ${ }^{14,20,22}$ Rather, treatments in $\mathrm{He}$ yield a combination of $\mathrm{ZCu}^{+}, \mathrm{ZCu}_{x} \mathrm{O}_{y} \mathrm{H}_{z}$, and $\mathrm{Z}_{2} \mathrm{Cu}$ species that do not auto-reduce. The Raman active $\mathrm{ZCuOCuZ}$ 
species seem unlikely to form via the dehydration of $\mathrm{ZCu}(\mathrm{OH})_{2} \mathrm{CuZ}$ (step 2, Scheme 1), because no Raman features appear at elevated temperatures in He (Figure 1a). We also used Raman spectrokinetics to measure rates of ZCuOCuZ formation over $\mathrm{Cu}-\mathrm{CHA}$-I samples treated in carbon monoxide ( $5 \mathrm{kPa} \mathrm{CO}, 96 \mathrm{kPa} \mathrm{He}, 523 \mathrm{~K}$ ), which fully reduces multinuclear $\mathrm{Cu}_{\mathrm{x}} \mathrm{O}_{\mathrm{y}}$ sites to $\mathrm{ZCu}^{+}{ }^{20}$ Following these $\mathrm{CO}$ pretreatments, we observe $\mathrm{ZCuOCuZ}$ formation rates that depend on $\mathrm{O}_{2}$ pressure, temperature, and $\mathrm{D}_{2} \mathrm{O} / \mathrm{H}_{2} \mathrm{O}$ (Section S8) similarly as Cu-CHA-I instead auto-reduced in He. These comparisons demonstrate that step 1 and step 2 are not kinetically relevant for the formation of the $\mathrm{ZCuOCuZ} \mathrm{complex}$ after a He auto-reduction treatment. Finally, we must note that this sequence of reactions (steps $1-3$, Scheme 1 ) does not involve gaseous $\mathrm{O}_{2}$; therefore, these steps do not explain the dependence of $\mathrm{ZCuOCuZ}$ formation rates on the pressure of $\mathrm{O}_{2}$ (Figs $4 \mathrm{a}$ and $4 \mathrm{~d}$ ). Consequently, the subsequent and slower formation of the Raman active $\mathrm{ZCuOCuZ} \mathrm{com-}$ plexes must reflect steps $6 \mathrm{a}$ or $6 \mathrm{~b}$ if $0-0$ bond rupture limits rates.

To test if our series of hypothetical steps can account for the observed rates of $\mathrm{ZCuOCuZ}$ formation, we derive a simple rate expression based on steps 4-6 in Scheme 1. In this model, the rate of $\mathrm{ZCuOCuZ}$ formation is given by

$$
\frac{d[\mathrm{ZCuOCuZ}]}{d t}=k_{6}\left[\mathrm{ZCuO}_{2} \mathrm{CuZ}\right]
$$

where $k_{i}$ represents the rate constant for step $i$, and [a] represents either the number of a given species (i.e., if it is a surface species, such as ZCuOCuZ) or the activity of the gasphase species (e.g., $\mathrm{O}_{2}$ ). Under these reaction conditions (i.e., low pressures and high temperatures), the activities are equal to the partial pressure. Step $6 \mathrm{~b}$ implies that ZCuOCuZ formation involves $\mathrm{H}_{2} \mathrm{O}$, which we rationalize as either solvation of the transition state for the $0-0$ bond rupture or evidence that proton transfer facilitates this event. Invoking the pseudo-steady state assumption on $\left[\mathrm{ZCuO}{ }_{2} \mathrm{CuZ}\right]$ and $\left[\mathrm{ZCuO}_{2}^{-}\right]$species simplifies equation 5 to yield

$$
\frac{d[\mathrm{ZCuOCuZ}]}{d t}=k_{4}\left[\mathrm{ZCu}^{+}\right]\left[\mathrm{O}_{2}\right]
$$

The expression for $\left[\mathrm{ZCu}^{+}\right]$arises from a site balance over all likely surface intermediates present in steps 4,5 , and 6

$$
\begin{aligned}
& {[L]=\left[\mathrm{ZCu}^{+}\right]+\left[\mathrm{ZCuO}_{2}^{-}\right]+\left[\mathrm{ZCuO}_{2} \mathrm{CuZ}\right]} \\
& {[L]=\left[\mathrm{ZCu^{+ }}\right]\left(1+\frac{k_{4}}{k_{5}}\left[\mathrm{O}_{2}\right]+\frac{k_{5}}{k_{6}}\left[\mathrm{O}_{2}\right]\left[\mathrm{ZCu}^{+}\right]\right)}
\end{aligned}
$$

where $[L]$ represents the total number of $\mathrm{Cu}$ ions that form Raman-active intermediates and the three terms within the parentheses of equation 8 correspond to the relative coverages of $\mathrm{ZCu}^{+}, \mathrm{ZCuO}_{2}$, and $\mathrm{ZCuO}_{2} \mathrm{CuZ}$ species, respectively. Substitution of equation 8 into equation 6 yields

$$
\frac{d[\text { ZCuOCuZ }]}{d t} \frac{1}{[L]}=\frac{k_{4}\left[O_{2}\right]}{\left(1+\frac{k_{4}}{k_{5}}\left[O_{2}\right]+\frac{k_{5}}{k_{6}}\left[O_{2}\right]\left[Z_{\left.C u^{+}\right]}\right]\right)}
$$

At low temperatures, the chemisorption of $\mathrm{O}_{2}$ is facile, which suggests that an $\mathrm{O}_{2}$-derived intermediate (e.g., $\mathrm{ZCuO}_{2}$ -
) comprises the most-abundant reactive intermediate (MARI). Equation 9 collapses to a simpler form with this approximation

$$
\frac{d[\text { ZCuOCuZ }]}{d t} \frac{1}{[L]}=k_{5}
$$

In contrast, the entropic losses incurred by $\mathrm{O}_{2}$ chemisorption prevail at higher temperatures, which leads to $\mathrm{ZCu}^{+}$as the MARI and reduces equation 9 to

$$
\frac{d[\mathrm{ZCuOCuZ}]}{d t} \frac{1}{[L]}=k_{4}\left[\mathrm{O}_{2}\right]
$$

Equations 10 and 11 quantitatively describe the $\mathrm{O}_{2}$ dependence on the rates of $\mathrm{ZCuOCuZ}$ formation, while the complex and likely non-elementary role of water molecules is captured within $k_{6}$ (Scheme 1).

While Scheme 1 and equations 5 - 9 yield functional expressions that describe $\mathrm{O}_{2}$ activation kinetics, we note that this series of chemical transformations arises largely from chemical intuition and experimental observations. The unambiguous identification of the elementary steps that lead to $\mathrm{ZCuOCuZ} \mathrm{formation} \mathrm{requires} \mathrm{a} \mathrm{combination} \mathrm{of} \mathrm{currently}$ inaccessible synthetic methods and DFT-calculated reaction trajectories. Furthermore, DFT-calculated reaction pathways to quantitatively evaluate the free energy landscape of $\mathrm{O}_{2}$ activation may not yield meaningful results to interpret experimental data, because the values calculated are a strong function of the $\mathrm{Al}$ arrangement that influences the binuclear $\mathrm{Cu}$ configurations chosen. Even nominally "singlesite" $\mathrm{Cu}$-CHA samples that contain only 6-MR isolated Al sites possess multiple types of Al-Al pair configurations in 8-MR windows that influence the energetics of binuclear $\mathrm{Cu}$-oxo species formed.

Collectively, these results present evidence for the involvement of the $\mathrm{ZCuOCuZ}$ complex as an active intermediate for PMO and a plausible series of chemical steps for $\mathrm{O}_{2}$ activation over $\mathrm{ZCuOH}$ sites consistent with the observed dependence of $\mathrm{O}_{2}$ activation on $\mathrm{O}_{2}$ and $\mathrm{H}_{2} \mathrm{O}$ pressure, protons, and temperature. The precise identification of binuclear $\mathrm{Cu}$ species responsible for a specific chemistry (e.g., NO decomposition, $\mathrm{CH}_{3} \mathrm{OH}$ synthesis), however, remains an important scientific challenge.

\subsection{CONCLUSIONS}

$\mathrm{Cu}$-ion exchanged $\mathrm{CHA}$ zeolites that contain detectable quantities of $\mathrm{ZCuOH}$ activate molecular $\mathrm{O}_{2}$ to form $\mathrm{Cu}_{\mathrm{x}} \mathrm{O}_{\mathrm{y}}$ species active for partial methane oxidation (PMO), nitrogen oxide decomposition, and carbon monoxide oxidation. Temporally-resolved resonance Raman spectroscopy $\left(\lambda_{\text {ex }}=\right.$ $532 \mathrm{~nm}$ ) evinces the genesis of reactive $\mathrm{Cu}_{\mathrm{x}} \mathrm{O}_{\mathrm{y}}$ species that form at $\mathrm{ZCuOH}$ sites via the activation of $\mathrm{O}_{2}$. The population of these Raman-active species correlate strongly with increases in the yield of methanol from stoichiometric PMO, whereas, rates of the bulk oxidation of $\mathrm{Cu}$ (I) to $\mathrm{Cu}$ (II) proceed significantly faster as observed with X-ray absorption spectroscopy. These kinetic comparisons suggest that kinetically-relevant structural rearrangements (and $0-0$ bond rupture) determine formation rates of the $\mathrm{Cu}_{\mathrm{x}} \mathrm{O}_{\mathrm{y}}$ complex responsible for methanol formation and that rates of $\mathrm{Cu}(\mathrm{I})$ oxidation do not correspond to the formation of the reactive intermediate. 
The Raman active $\mathrm{Cu}_{\mathrm{x}} \mathrm{O}_{\mathrm{y}}$ complex possesses a distinct vibrational feature at $603 \mathrm{~cm}^{-1}$ assigned to the deformational mode of the 8-membered ring of a mono( $\mu$-oxo)dicopper intermediate ( $\mathrm{ZCuOCuZ),} \mathrm{through} \mathrm{comparisons} \mathrm{of} \mathrm{measured}$ spectra with Raman scattering frequencies calculated via density functional theory. The rates of $\mathrm{O}_{2}$ activation of ZCuOH-containing CHA samples show two distinct kinetic regimes at low (<673 K) and high ( $>685 \mathrm{~K})$ temperatures. At low temperatures, rates of $\mathrm{O}_{2}$ activation do not depend on $\mathrm{O}_{2}$ pressure, show a first-to-zeroth order kinetic dependence on $\mathrm{H}_{2} \mathrm{O}$ pressure, and exhibit a normal $\mathrm{H}_{2} \mathrm{O} / \mathrm{D}_{2} \mathrm{O}$ KIE. At high temperatures, $\mathrm{O}_{2}$ activation rates increase linearly with $\mathrm{O}_{2}$ pressure, show a weak dependence on $\mathrm{H}_{2} \mathrm{O}$ pressure, and possess a normal $\mathrm{KIE}$ on $\mathrm{H}_{2} \mathrm{O} / \mathrm{D}_{2} \mathrm{O}$. These observations agree with a plausible mechanism in which a fraction of $\mathrm{ZCuOH}$ sites initially reduce to form $\mathrm{ZCu}^{+}$sites and readily bind molecular $\mathrm{O}_{2}$ to form $\mathrm{ZCuO}_{2}$ intermediates. $\mathrm{ZCu}^{+}$and $\mathrm{ZCuO}_{2}$ then react to form a $\mathrm{ZCuO}_{2} \mathrm{CuZ}$ complex. These $\mathrm{ZCuO}_{2} \mathrm{CuZ}$ intermediates undergo kinetically relevant $0-0$ bond scission, which can be facilitated by water, to form $\mathrm{ZCuOCuZ}$ species and $\mathrm{O}^{2-}$.

These data, methodologies, and interpretation provide a basis to understand how $\mathrm{Cu}$ ions within zeolites activate $\mathrm{O}_{2}$ and evolve to form species responsible for socially- and environmentally-important oxidation chemistries. The precise identification of the active species and the development of design principles that increase rates and selectivities remains a challenge. These goals motivate the development of synthetic methods to prepare model $\mathrm{Cu}$-zeolites with more uniform $\mathrm{Cu}$ structures, innovative kinetic and spectroscopic tools to probe active $\mathrm{Cu}$ structures, and connections between experimental data and computational models to understand these complex systems.

\section{ASSOCIATED CONTENT}

Supporting Information. CHA synthesis methods, $\mathrm{Cu}$ ion exchange, UV-vis spectroscopy, Cu-CHA characterization, in situ $\mathrm{X}$-ray absorption spectroscopy, methanol yields, simulated Raman spectra, in situ Raman spectrokinetics on CO-reduced $\mathrm{Cu}-$ CHA-I

\section{AUTHOR INFORMATION}

\section{Corresponding Author \\ *dwflhrty@illinois.edu}

\section{Author Contributions}

The manuscript was written through contributions of all authors. All authors have given approval to the final version of the manuscript.

\section{ACKNOWLEDGMENT}

We thank Abinaya Sampath (Illinois) for technical assistance in setting up Raman spectrokinetic measurements, and Prof. Jeffrey Miller and Nicole LiBretto (Purdue) for XAS data analysis and fitting. D.T.B. acknowledges a National Defense Science and Engineering Graduate Fellowship from the Department of Defense and a Dissertation Completion Fellowship from the University of Illinois. Research at the University of Illinois on Raman spectrokinetic measurements was supported by the Department of Energy, Office of Science, Office of Basic Energy
Sciences, under Award Number DE-SC0020224. Research at Purdue University on zeolite synthesis and characterization was supported by the U.S. Department of Energy, Office of Science, Office of Basic Energy Sciences, under Award Number DESC0019026 and an Alfred P. Sloan Research Fellowship. Use of the Advanced Photon Source is supported by the U.S. Department of Energy, Office of Science, and Office of Basic Energy Sciences, under Contract no. DE-AC02-06CH11357. MRCAT operations and beamline 10-ID are supported by the Department of Energy and the MRCAT member institutions. We also thank Sachem, Inc. for providing the organic structure-directing agent used to synthesize SSZ-13. The authors acknowledge Research Computing at the University of Virginia for providing computational resources and technical support that have contributed to the results reported within this publication. C.P and C.L. acknowledge funding provided by the National Science Foundation (CBET-1942015).

\section{REFERENCES}

1. Groothaert, M. H.; Van Bokhoven, J. A.; Battiston, A. A.; Weckhuysen, B. M.; Schoonheydt, R. A., Bis( $\mu$-oxo)dicopper in Cu-ZSM-5 and Its Role in the Decomposition of NO: A Combined in Situ XAFS, UV-Vis-Near-IR, and Kinetic Study. J. Am. Chem. Soc. 2003, 125, 7629-7640.

2. Da Costa, P.; Modén, B.; Meitzner, G. D.; Lee, D. K.; Iglesia, E., Spectroscopic and chemical characterization of active and inactive $\mathrm{Cu}$ species in NO decomposition catalysts based on Cu-ZSM5. Phys. Chem. Chem. Phys. 2002, 4, 4590-4601.

3. Sengupta, D.; Schneider, W. F.; Hass, K. C.; Adams, J. B., CO oxidation catalyzed by $\mathrm{Cu}$-exchanged zeolites: a density functional theory study. Catal. Lett. 1999, 61, 179-186.

4. Matsumoto, H.; Tanabe, S., Catalytic Behavior and Structure of Active Species of $\mathrm{Cu}-\mathrm{Y}$ Zeolite in Oxidation of Carbon Monoxide. J. Phys. Chem. 1990, 94, 4207-4212.

5. Jones, C. B.; Khurana, I.; Krishna, S. H.; Shih, A. J.; Delgass, W. N.; Miller, J. T.; Ribeiro, F. H.; Schneider, W. F.; Gounder, R., Effects of dioxygen pressure on rates of $\mathrm{NO}_{\mathrm{x}}$ selective catalytic reduction with $\mathrm{NH}_{3}$ on Cu-CHA zeolites. J. Catal. 2020, 389, 140-149.

6. Paolucci, C.; Khurana, I.; Parekh, A. A.; Li, S.; Shih, A. J.; Li, H.; Di Iorio, J. R.; Albarracin Caballero, J. D.; Yezerets, A.; Miller, J. T.; Delgass, N. W.; Ribeiro, F. H.; Schneider, W. F.; Gounder, R., Dynamic multinuclear sites formed by mobilized copper ions in $\mathrm{NO}_{\mathrm{x}}$ selective catalytic reduction. Science 2017, 357, 898-903.

7. Paolucci, C.; Parekh, A. A.; Khurana, I.; Di Iorio, J. R.; Li, H.; Albarracin Caballero, J. D.; Shih, A. J.; Anggara, T.; Delgass, W. N.; Miller, J. T.; Ribeiro, F. H.; Gounder, R.; Schneider, W. F., Catalysis in a Cage: Condition-Dependent Speciation and Dynamics of Exchanged Cu Cations in SSZ-13 Zeolites. J. Am. Chem. Soc. 2016, 138 (18), 6028-6048.

8. Shih, A. J.; Khurana, I.; Li, H.; González, J.; Kumar, A.; Paolucci, C.; Lardinois, T. M.; Jones, C. B.; Albarracin Caballero, J. D.; Kamasamudram, K.; Yezerets, A.; Delgass, W. N.; Miller, J. T.; Villa, A. L.; Schneider, W. F.; Gounder, R.; Ribeiro, F. H., Spectroscopic and kinetic responses of $\mathrm{Cu}-\mathrm{SSZ}-13$ to $\mathrm{SO}_{2}$ exposure and implications for $\mathrm{NO}_{\mathrm{x}}$ selective catalytic reduction. Appl. Catal. A 2019, 574, 122-131.

9. Krishna, S. H.; Jones, C. B.; Miller, J. T.; Ribeiro, F. H.; Gounder, R., Combining Kinetics and Operando Spectroscopy to Interrogate the Mechanism and Active Site Requirements of NOx Selective Catalytic Reduction with $\mathrm{NH}_{3}$ on $\mathrm{Cu}$-Zeolites. J Phys. Chem. Lett. 2020, 11 (13), 5029-5036.

10. Groothaert, M. H.; Smeets, P. J.; Sels, B.; Jacobs, P. A.; Schoonheydt, R. A., Selective Oxidation of Methane by the Bis( $\mu$-oxo)dicopper Core Stabilized on ZSM-5 and Mordenite Zeolites. J. Am. Chem. Soc. 2005, 127, 1394-1395.

11. Woertink, J. S.; Smeets, P. J.; Groothaert, M. H.; Vance, M. A.; Sels, B. F.; Schoonheydt, R. A.; Solomon, E. I., A $\left[\mathrm{Cu}_{2} \mathrm{O}\right]^{2+}$ core in $\mathrm{Cu}-\mathrm{ZSM}-5$, the active site in the oxidation of methane to 
methanol. Proc. Natl. Acad. Sci. 2009, 106 (45), 1890818913.

12. Dinh, K. T.; Sullivan, M. M.; Serna, P.; Meyer, R. J.; Dincă, M. Román-Leshkov, Y., Viewpoint on the Partial Oxidation of Methane to Methanol Using $\mathrm{Cu}$ - and Fe-Exchanged Zeolites. ACS Catal. 2018, 8 (9), 8306-8313.

13. Pappas, D. K.; Martini, A.; Dyballa, M.; Kvande, K.; Teketel, S. Lomachenko, K. A.; Baran, R.; Glatzel, P.; Arstad, B.; Berlier, G.; Lamberti, C.; Bordiga, S.; Olsbye, U.; Svelle, S.; Beato, P. Borfecchia, E., The Nuclearity of the Active Site for Methane to Methanol Conversion in Cu-Mordenite: A Quantitative Assessment. J. Am. Chem. Soc. 2018, 140 (45), 15270-15278.

14. Pappas, D. K.; Borfecchia, E.; Dyballa, M.; Pankin, I. A.; Lomachenko, K. A.; Martini, A.; Signorile, M.; Teketel, S.; Arstad, B.; Berlier, G.; Lamberti, C.; Bordiga, S.; Olsbye, U.; Lillerud, K. P.; Svelle, S.; Beato, P., Methane to Methanol: Structure-Activity Relationships for Cu-CHA. J. Am. Chem. Soc. 2017, 139 (42), 14961-14975.

15. Borfecchia, E.; Pappas, D. K.; Dyballa, M.; Lomachenko, K. A.; Negri, C.; Signorile, M.; Berlier, G., Evolution of active sites during selective oxidation of methane to methanol over $\mathrm{Cu}$ CHA and Cu-MOR zeolites as monitored by operando XAS. Catal. Today 2019, 333, 17-27.

16. Alayon, E. M.; Nachtegaal, M.; Bodi, A.; Ranocchiari, M.; van Bokhoven, J. A., Bis(mu-oxo) versus mono(mu-oxo)dicopper cores in a zeolite for converting methane to methanol: an in situ XAS and DFT investigation. Phys. Chem. Chem. Phys. 2015, 17 (12), 7681-93.

17. Brezicki, G.; Kammert, J. D.; Gunnoe, T. B.; Paolucci, C.; Davis, R. J., Insights into the Speciation of $\mathrm{Cu}$ in the $\mathrm{Cu}-\mathrm{H}$-Mordenite Catalyst for the Oxidation of Methane to Methanol. ACS Catal. 2019, 9 (6), 5308-5319.

18. Dinh, K. T.; Sullivan, M. M.; Narsimhan, K.; Serna, P.; Meyer, R. J.; Dinca, M.; Roman-Leshkov, Y., Continuous Partial Oxidation of Methane to Methanol Catalyzed by DiffusionPaired Copper Dimers in Copper-Exchanged Zeolites. J. Am. Chem. Soc. 2019, 141 (29), 11641-11650.

19. Narsimhan, K.; Iyoki, K.; Dinh, K.; Roman-Leshkov, Y., Catalytic Oxidation of Methane into Methanol over CopperExchanged Zeolites with Oxygen at Low Temperature. ACS Cent Sci 2016, 2 (6), 424-429.

$20 . \quad$ Li, H.; Paolucci, C.; Khurana, I.; Wilcox, L. N.; Goltl, F.; Albarracin-Caballero, J. D.; Shih, A. J.; Ribeiro, F. H.; Gounder, R.; Schneider, W. F., Consequences of exchange-site heterogeneity and dynamics on the UV-visible spectrum of Cu-exchanged SSZ-13. Chem Sci 2019, 10 (8), 2373-2384.

21. Tomkins, P.; Ranocchiari, M.; van Bokhoven, J. A., Direct Conversion of Methane to Methanol under Mild Conditions over $\mathrm{Cu}$-Zeolites and beyond. Acc. Chem. Res. 2017, 50 (2), 418-425.

22. Ipek, B.; Wulfers, M. J.; Kim, H.; Göltl, F.; Hermans, I.; Smith, J. P.; Booksh, K. S.; Brown, C. M.; Lobo, R. F., Formation of $\left[\mathrm{Cu}_{2} \mathrm{O}_{2}\right]^{2+}$ and $\left[\mathrm{Cu}_{2} \mathrm{O}\right]^{2+}$ toward $\mathrm{C}-\mathrm{H}$ Bond Activation in $\mathrm{Cu}-$ SSZ-13 and Cu-SSZ-39. ACS Catal. 2017, 7 (7), 4291-4303.

23. Vanelderen, P.; Hadt, R. G.; Smeets, P. J.; Solomon, E. I.; Schoonheydt, R. A.; Sels, B. F., Cu-ZSM-5: A biomimetic inorganic model for methane oxidation. J. Catal. 2011, 284 (2), 157-164.

24. Vanelderen, P.; Snyder, B. E.; Tsai, M. L.; Hadt, R. G.; Vancauwenbergh, J.; Coussens, O.; Schoonheydt, R. A.; Sels, B. F.; Solomon, E. I., Spectroscopic definition of the copper active sites in mordenite: selective methane oxidation. J. Am Chem. Soc. 2015, 137 (19), 6383-6392.

25. Nachtigall, P.; Arean, C. O., Themed Issue on characterization of adsorbed species. Phys. Chem. Chem. Phys. 2010, 12 (24), 6307-6308.

26. Knorpp, A.; Pinar, A. B.; Baerlocher, C.; McCusker, L. B.; Casati, N.; Newton, M. A.; Checchia, S.; Meyet, J.; Palagin, D. van Bokhoven, J. A., Paired copper monomers in zeolite omega: the active site for methane-to-methanol conversion Angew. Chem. Int. Ed. 2020, 60, 1-6.

27. Grundner, S.; Markovits, M. A.; Li, G.; Tromp, M.; Pidko, E. A.; Hensen, E. J.; Jentys, A.; Sanchez-Sanchez, M.; Lercher, J. A. Single-site trinuclear copper oxygen clusters in mordenite for selective conversion of methane to methanol. Nat Commun. 2015, 6, 7546.

28. Li, G.; Vassilev, P.; Sanchez-Sanchez, M.; Lercher, J. A.; Hensen, E. J. M.; Pidko, E. A., Stability and reactivity of copper oxo-clusters in ZSM-5 zeolite for selective methane oxidation to methanol. J. Catal. 2016, 338, 305-312.

29. Grundner, S.; Luo, W.; Sanchez-Sanchez, M.; Lercher, J. A., Synthesis of single-site copper catalysts for methane partial oxidation. Chem. Commun. 2016, 52 (12), 2553-2556.

30. Newton, M. A.; Knorpp, A. J.; Sushkevich, V. L.; Palagin, D.; van Bokhoven, J. A., Active sites and mechanisms in the direct conversion of methane to methanol using $\mathrm{Cu}$ in zeolitic hosts: a critical examination. Chem. Soc. Rev. 2020, 49 (5), 1449-1486.

31. Sushkevich, V. L.; Palagin, D.; van Bokhoven, J. A., The Effect of the Active-Site Structure on the Activity of Copper Mordenite in the Aerobic and Anaerobic Conversion of Methane into Methanol. Angew. Chem. Int. Ed. Engl. 2018, 57 (29), 8906-8910.

32. Borfecchia, E.; Beato, P.; Svelle, S.; Olsbye, U.; Lamberti, C.; Bordiga, S., Cu-CHA - a model system for applied selective redox catalysis. Chem. Soc. Rev. 2018, 47 (22), 8097-8133.

33. Di Iorio, J. R.; Gounder, R., Controlling the Isolation and Pairing of Aluminum in Chabazite Zeolites Using Mixtures of Organic and Inorganic Structure-Directing Agents. Chem. Mater. 2016, 28 (7), 2236-2247.

34. Devos, J.; Bols, M. L.; Plessers, D.; Goethem, C. V.; Seo, J. W.; Hwang, S.-J.; Sels, B. F.; Dusselier, M., Synthesis-StructureActivity Relations in Fe-CHA for C-H Activation: Control of Al Distribution by Interzeolite Conversion. Chem. Mater 2019, 32 (1), 273-285.

35. Koishybay, A.; Shantz, D. F., Water Is the Oxygen Source for Methanol Produced in Partial Oxidation of Methane in a Flow Reactor over Cu-SSZ-13. J. Am. Chem. Soc. 2020, 142, 11962-11966.

36. Sushkevich, V. L.; Palagin, D.; Ranocchiari, M.; Van Bokhoven, J. A., Selective anaerobic oxidation of methane enables direct synthesis of methanol. Science 2017, 356, 523-527.

37. Witzke, M. E.; Almithn, A.; Coonrod, C. L.; Triezenberg, M. D.; Hibbitts, D. D.; Flaherty, D. W., In Situ Methods for Identifying Reactive Surface Intermediates during Hydrogenolysis Reactions: C-O Bond Cleavage on Nanoparticles of Nickel and Nickel Phosphides. J. Am. Chem. Soc. 2019, 141, 16671-16684.

38. Kresse, G.; Furthmüller, J., Efficient iterative schemes for ab initio total-energy calculations using a plane-wave basis set Phys. Rev. B 1996, 54, 11169-11184.

39. Grimme, S.; Antony, J.; Ehrlich, S.; Krieg, H., A consistent and accurate ab initio parametrization of density functional dispersion correction (DFT-D) for the 94 elements H-Pu. $J$. Chem. Phys. 2010, 132 (15), 154104.

40. Grimme, S.; Ehrlich, S.; Goerigk, L., Effect of the damping function in dispersion corrected density functional theory. $J$. Comput. Chem. 2011, 32 (7), 1456-1465.

41. Blöchl, P. E., Projector augmented-wave method. Phys. Rev. B 1994, 50 (24), 17953-17979.

42. Chen, L.; Janssens, T. V. W.; Gronbeck, H., A comparative test of different density functionals for calculations of $\mathrm{NH}_{3}$-SCR over Cu-Chabazite. Phys. Chem. Chem. Phys. 2019, 21 (21), 10923-10930

43. Liang, Q.; Dwaraknath, S.; Persson, K. A., High-throughput computation and evaluation of raman spectra. Sci. Data 2019, 6 (1), 135.

44. Sushkevich, V. L.; van Bokhoven, J. A., Revisiting copper reduction in zeolites: the impact of autoreduction and sample synthesis procedure. Chem. Commun. 2018, 54 (54), 7447-7450.

45. Garrido, M.; Rius, F. X.; Larrechi, M. S., Multivariate curve resolution-alternating least squares (MCR-ALS) applied to spectroscopic data from monitoring chemical reactions processes. Anal Bioanal Chem 2008, 390 (8), 2059-2066.

46. Wu, L.; Degirmenci, V.; Magusin, P. C. M. M.; Lousberg, N. J. H. G. M.; Hensen, E. J. M., Mesoporous SSZ-13 zeolite prepared 
by a dual-template method with improved performance in the methanol-to-olefins reaction. J. Catal. 2013, 298, 27-40.

47. Dutta, P. K.; Puri, M., Synthesis and Structure of Zeolite ZSM5: A Raman Spectroscopic Study. J. Phys. Chem. 1987, 91, 4329-4333.

48. Zones, S. I., Conversion of Faujasites to High-Silica Chabazite SSZ-13 in the Presence of NNN-Trimethyl-1adamantammonium Iodide. J. Chem. Soc., Faraday Trans. 1991, 87, 3709-3716.

49. Fischer, M.; Delgado, M. R.; Areán, C. O.; Duran, C. O., CO adsorption complexes in zeolites: How does the inclusion of dispersion interactions affect predictions made from DFT calculations? The case of Na-CHA. Theor. Chem. Acc. 2015, 134:91.

50. Zhang, R.; McEwen, J.-S.; Kollár, M.; Gao, F.; Wang, Y.; Szanyi, J.; Peden, C. H. F., NO Chemisorption on Cu/SSZ-13: A Comparative Study from Infrared Spectroscopy and DFT Calculations. ACS Catal. 2014, 4 (11), 4093-4105.

51. For example, over the course of $1 \mathrm{ks}$, the molar ratio of dioxygen to total $\mathrm{Cu}$ within the sample is $>5,000$.

52. Step 5 is assumed to be irreversible because the heterolytic cleavage of $\mathrm{ZCuO}_{2} \mathrm{CuZ}$ to form $\mathrm{ZCuO}_{2}^{-}$and $\mathrm{ZCu}^{+}$is energetically disfavored. 
Table of Contents

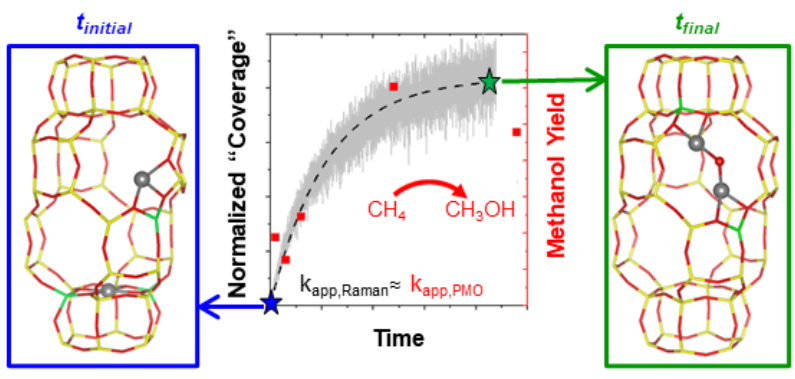

